$11: 2$

1

NOV 191993

OSTI
UCRL-ID 112779

Reprinted from Engineering Research, Development, and Technology.

Thrust Area Report FY 92

UCRL 53868-92

\title{
Emerging Technologies
}

\section{Shin-yee Lu}

March, 1993

This is an informal report intended primarily for internal or limited external distribution. The opinions and conclusions stated are those of the author and may or may not be those of the Laboratory. Work performed under the auspices of the U.S. Department of Energy by the Lawrence Livermore National Laboratory under Contract W-7405-Eng-48. 
Disclaimer

This document was prepared as an account of work sponsored by an agency of the United States Government. Neither the United States Government nor the University of California nor any of their employees, makes any warranty, express or implied, or assumes any legal liability or responsibility for the accuracy, completeness, or usefulness of any information, apparatus, product, or process disclosed, or represents that its use would not infringe privately owned rights. Reference herein to any specific commercial products, process, or service by trade name, trademark, manufacturer, or otherwise, does not necessarily constitute or imply its endorsement, recommendation, or favoring by the United States Government or the University of California. The views and opinions of authors expressed herein do not necessarily state or reflect those of the United States Government or the University of California and shall not be used for advertising or product endorsement purposes.

This report has been reproduced

directly from the best available copy.

Available to DOE and DOE contractors from the Office of Scientific and Technical Information P.O. Box 62, Oak Ridge, TN 37831

Prices available from (615) 576-8401, FTS 626-8401

Available to the public from the National Technical Information Service U.S. Department of Commerce 5285 Port Royal Rd., Springfield, VA 22161 


\title{
Emerging Technologies
}

\author{
Shin-yee Lu
}




\section{Emerging Technologies}

The mission of the Emerging Technologies thrust area at Lawrence Livermore National Laboratory is to help individuals establish technology areas that have national and commercial impact, and are outside the scope of the existing thrust areas.

Wecontinue toencourageinnovativeideas

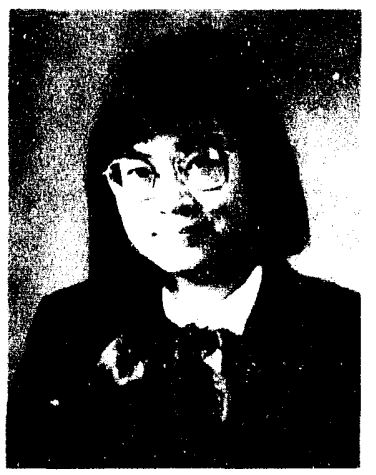
that bring quality results to existing programs. We also take as our mission the encouragement of investment in new technology areas that are important to the economic competitiveness of this nation.

In fiscal year 1992, we have focused on nine projects, summarized in this report: (1) Tire, Accident, Handling, and Roadway Safety; (2) EXTRANSYT: An Expert System for
Advanced Traffic Management; (3) Odin: A HighPower, Underwater, Acoustic Transmitter for Surveillance Applications; (4) Passive Seismic Reservoir Monitoring: Signal Processing Innov ations; (5) Paste Extrudable Explosive Aft Charge for Multi-Stage Munitions; (6) A Continuum Model for Reinforced Concrete at High Pressures and Strain Rates: Interim Report; (7) Benchmarking of the Criticality Evaluation Cote $\mathrm{COG}$; (8) Fast Algorithm for Large-Scale Consensus DNA Sequence Assembly; and (9) Using Electrical Heating To Enhance the Extraction of Volatile Organic Compounds from Sovil.

Shin-yee Lu Thrust Aren Le'uder 
Section 4

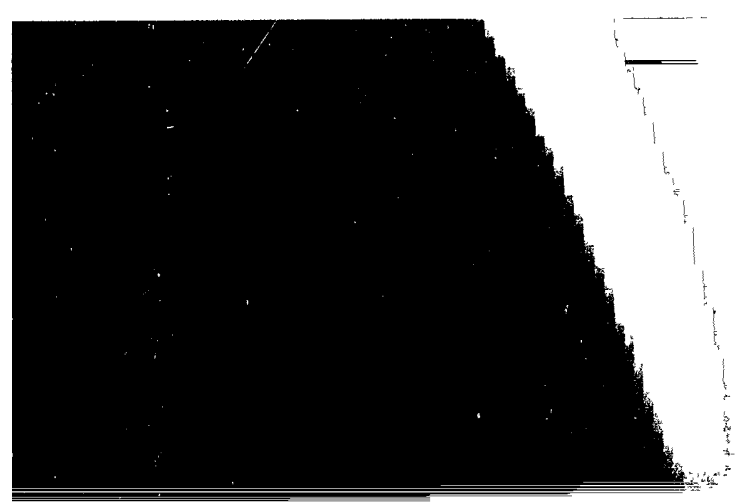

1

$=$

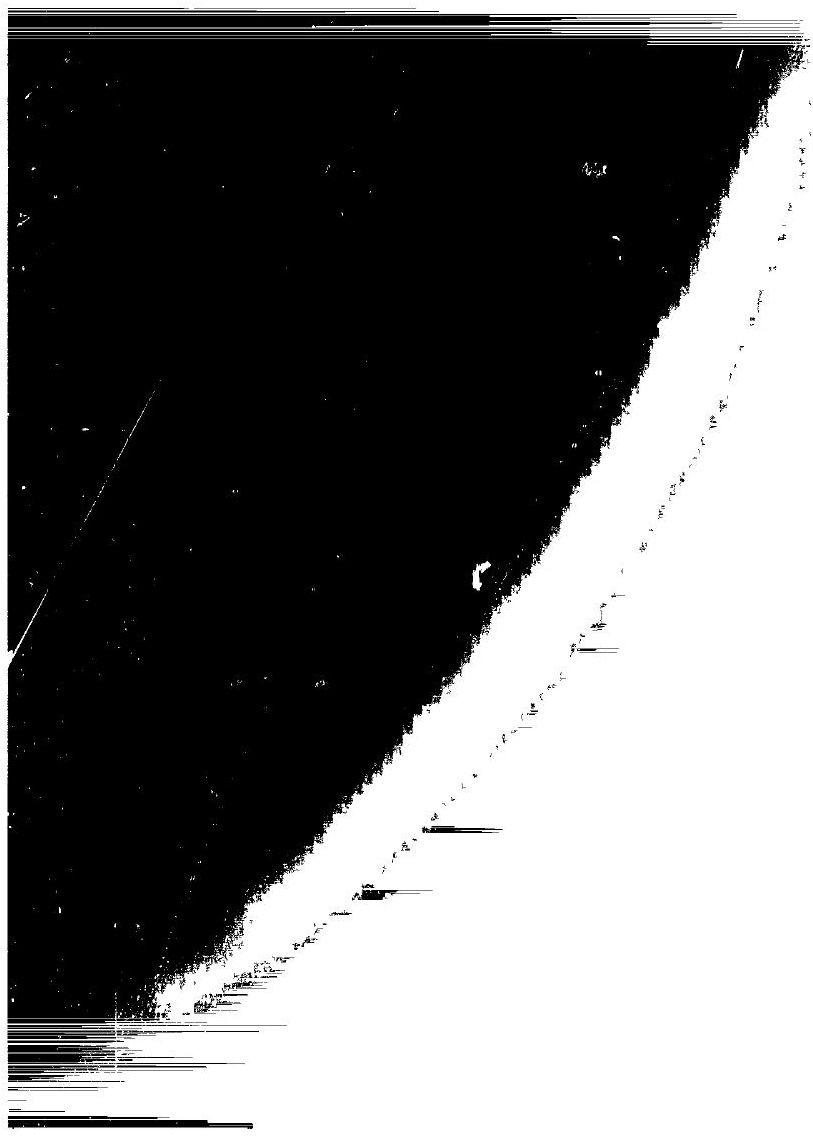




\section{Emerging Technologies}

Overview

Shin-yee Lu, Tlurust Aren Leader

Tire, Accident, Handling, and Roadway Safety

Roger W. Logan

EXTRANSYT: An Expert System for Advanced Traffic Management

Rowland R. Jolmson 49

Odin: A High Power, Underwater, Acoustic Transmitter for Surveillance Applications

Terry R. Donich, Scott W. McAllister, and Charles S. Landram

Passive Seismic Reservoir Monitoring: Signal Processing Innovations

Darvid B. Harris, Robert J. Sherwood, Stephen P. Jarpe, and

David C. DeMartini

Paste Extrudable Explosive Aft Charge for Multi-stage Munitions

Douglas R. Faux and Russell W. Rosinsky

A Continuum Model for Reinforced Concrete at High Pressures and Strain Rates

Kurt H. Sinz.

Benchmarking of the Criticality Evaluation Code COG

William R. Lloyt, John S. Pearson, and H. Peter Alesso

Fast Algorithm for Large-Scale Consensus DNA Sequence Assembly

Shin-yee Lu, Elbert W. Branscomb, Michael E. Colinin, and

Richard S. Jutson

Using Electrical Heating To Enhance the Extraction of Volatile Organic Compounds from Soil

H. Michael Buettner and William D. Daily 


\title{
Tire, Accident, Handling, and Roadway Safety
}

\author{
Roger W. Logan \\ Nuclear Explosives Engincering \\ Mechanical Engineering
}

We are developing technology for an integrated package for the analysis of vehicle handling and of vehicle impact into roadside features and other vehicles. The program involves the development and use of rigid-body algorithms and the finite-element codes, DYNA and NIKE. Our goal is a tool for use by highway engineers at the Federal Highway Administration and state Departments of Transportation that allows good quantitative results at the workstation level. Our work has involved integration of handling and deformation codes, development of material and tire models, and comparisons of our results to test data.

\section{Introduction}

Our Tire, Accident, Handling, and Roadway Safety (TAHRS) project at Lawrence Livermore National Laboratory (LLNL) provides technical advances to be used in an externally funded program for Vehicle ImpactSimulation Technology. Advancement (VISTA), to begin on a small scale in FY-93.

The goal of the TAHRS initiative is to develop the technical capability to accurately model vehicle/barrier crash and post-crash behavior (Fig. 1). An improved analysis capability will improve highway barrier (and possibly vehicle) designs to minimize risk to occupants, and the hazards due to post-crash vehicle motion. These technical developments will become an integral part of the VISTA program. The goal of VISTA is to integrate the entire state of technology, including DYNA3D, NIKE3D, - TAHRS, and other world wide developments, into a user-friendly highway design tool useful at various levels of expertise.

The current state of the art in barrier design and post-crash dynamics involves a mixture of actual testing using instrumented vehicles, and empiri$\mathrm{cal} /$ numerical modeling using small, personal computer-based codes. These codes have been developed over many years; their empirical aspects have been tuned against crash test data. They are useful tools, but their relative lack of physics leaves them open to technical or legal doubt when extrapolation is involved. As an alternative, LLNL's three-dimensional (3-D) NIKE and
DYNA codes could be used separately or coupled to analyze the vehicle/barrier crash interaction. Recently, a Federal Highway Administration (FHWA) contract on this topic concluded that DYNA3D is the code of choice on which to form a VISTA program. The incentive for VISTA is quite strong, since about 40,000 traffic deaths occur each year in this country. As a direct consequence, about 40 billion dollars worth of lawsuits are active at any given time. Often state Departments of Transportation (DOT's) are the targets of these lawsuits. More than half of the fatal accidents typically involve only one vehicle. Thus, the ability to model and analyze barrier crash and post-crash motion with physics-based tools like NIKE, DYNA, and an integrated real-time handling (RTH) capability, could provide a strong supplemental tool for sorting out areas of responsibility.

\section{Progress}

The TAHRS technical efforts are organized into four overlapping areas: (1) vehicle handling and interfacing; (2) roadside features and component modeling; (3) vehicle models and integrated analysis; and (4) test data and validation. Highlights of progress in each area are summarized below.

\section{Vehicle Handling and Interfacing}

This technical area involves developments in the simulation of vehicle handling, linkage of RTH 


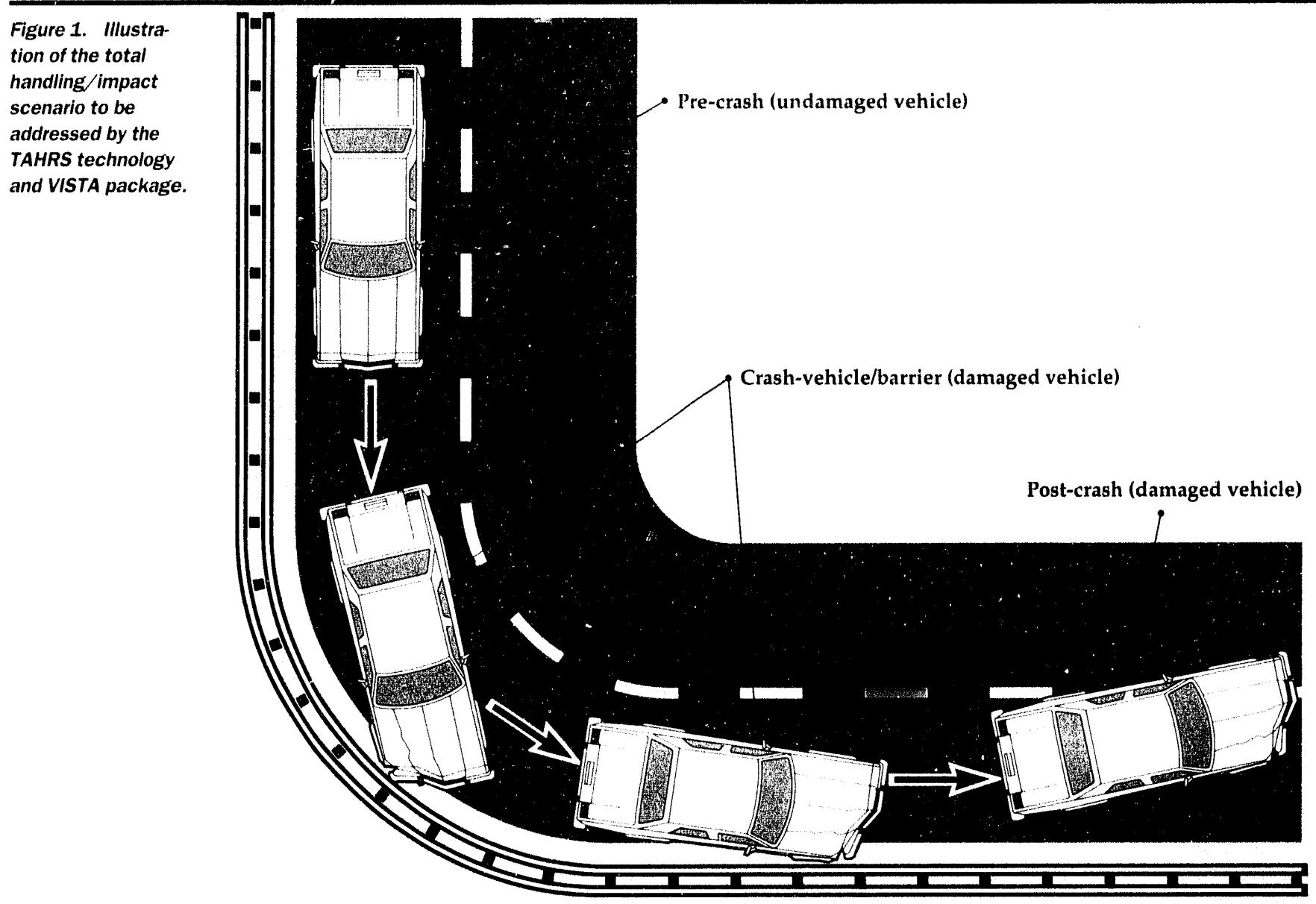

and finite element mesh (FEM) cotes, and development of an informative user interface.

In preparation for the linkage of RTH tand FEM cote's, a sterering force boundary condition is being added to NIKE:31). The lateral fores generated by cach tire can be computed by the inclusion of a tire mextel subroutine in NIKE:3D). The vecter diagram in Fig. 2a illustrates how NIKE3D) computes the lateral load on the tire. Simulating the road as a stome Wall, NIKE:3D first determines the vertical load on the tire. Then, using the user-input driver stering angle, $\theta$, the vehicle orientation direction, A, and velocity, V, NIKL:31) determines the tire slip angle, (e. NIKE3D) then use's a complex tire model to determine the lateral load, $L$, as a function of these variables. Figure 2 b shows top riews of a car moxtel during two simulations. Identical driver input is used: the wherel is turned first to the left, then to the right. The $25-m p h$ simulation results in a circular path; in the 45 -mph casce, the car skids into an unstableoversteer condition.

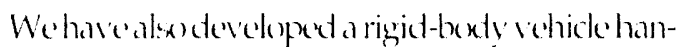
dling cexte called AUT(Sil IV) to demomstrate the linkage (x)th to NIKE, D) NA, and the user interface. This axte and others an be used to simulate the rehicle drmamics before and after the contact, and subseyuent deformations of the vehicle. Upron contact deetertion, data from the motel is passed to the finite element code, which simulates the dymamics of the vehicle during the collision. If the accident is such that the rehick disengages from contact with the barrier, the new, deformed vehicleconfiguration and the dymamic conditions can be pasised back to the rigid-bexty mextel for continued simulation. The s'e hicle onfiguration is fully 3-1), rigid-boxty, with 10 degrexs of frextom. There is one sprung moss and four independently suspended unsprung masses (wherls). The wherls, which are comnerted to the sprung mass with a spring and damper, are constrained tomoseperpendicular to the vehicke, Another set of springs and dampers are used to mextel the deformation of the wherels, which are free to leare the ground sturface. The ground, however, is limited to a flat plane. The vehicle velexity can be controlled by specifying driving forces or a desired velexity. Stex'ring cain be acomplished either by sperifying a table of sterring angles or by designating a path that the sterring control will attempt for follow. This results in

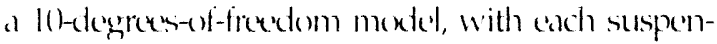
sionolement representext by a spring and domper, as 
is each unsprung mass. The tire forces are modeled using the Dugoff tire moxtel and are limited using the friction circle concept. Control of the vehicle during a run is currently accomplished by completing tables in a data file. Vehicle velocity can be controlled by specifying a desired speed or by inputting a table of driving forces vs time. Steering, likewise, can be controlled in two ways. One way is to specify a table of steering angles vs time, and the other is to specify a table of $x-y$ corordinate pairs representing the desired path of the vehicle. An imbedded steering controller will then attempt to follow the path as closely as possible.

To provide the interfaces among the user, $\mathrm{AU}$ TOSLED, NIKE, and DYNA, a simulation program has been developed to read an output file from AUTOSLED, and display pertinent information in an interactive graphics environment. A typical session using this simulation program is shown in Fig. 3. In the upper left corner of the window, an oval racetrack is shown with a rectangle representing the car. The user has the option of displaying or not displaying the racetrack. In addition, outlines of some of the car's previous positions are shown. The frequency with which these outlines are shown is another option controlled by the user. This view displays both position and yaw of the vehicle. To the right of the track are four gauges. These display suspension forces on the tires as the car follows the path. Next to the gauges are friction circles, which convey information about the normal, longitudinal, and lateral forces experienced by the tires. A constant diameter circle is based on initial forces on the tire when the car is stationary. Below this, steering angles and slip angles are shown. At the lower left corner, a rear view of the car is shown, giving the user information about the roll angle. To the right of this, a speedometer displays vehicle speed in miles per hour. The maximum speed on the speedomet $r$ is based on the maximum speed the vehicle re ches during the simulation. A pop-up shell next io the speedometer lets the user create strip charts using any of the 48 variables from the AUTOSLED output file. For example, one could plot lateral forces at tire 1 vs pitch of the vehicle. In the figure shown, the $y$ coordinate of the center of gravity is plotted against time.

\section{Roadside Features and Component Modeling}

Before embarking on a 'big picture' analysis of vehicle and roadside barrier under linked handling and impact conditions, it is necessary to consider the FEM deformation analysis of

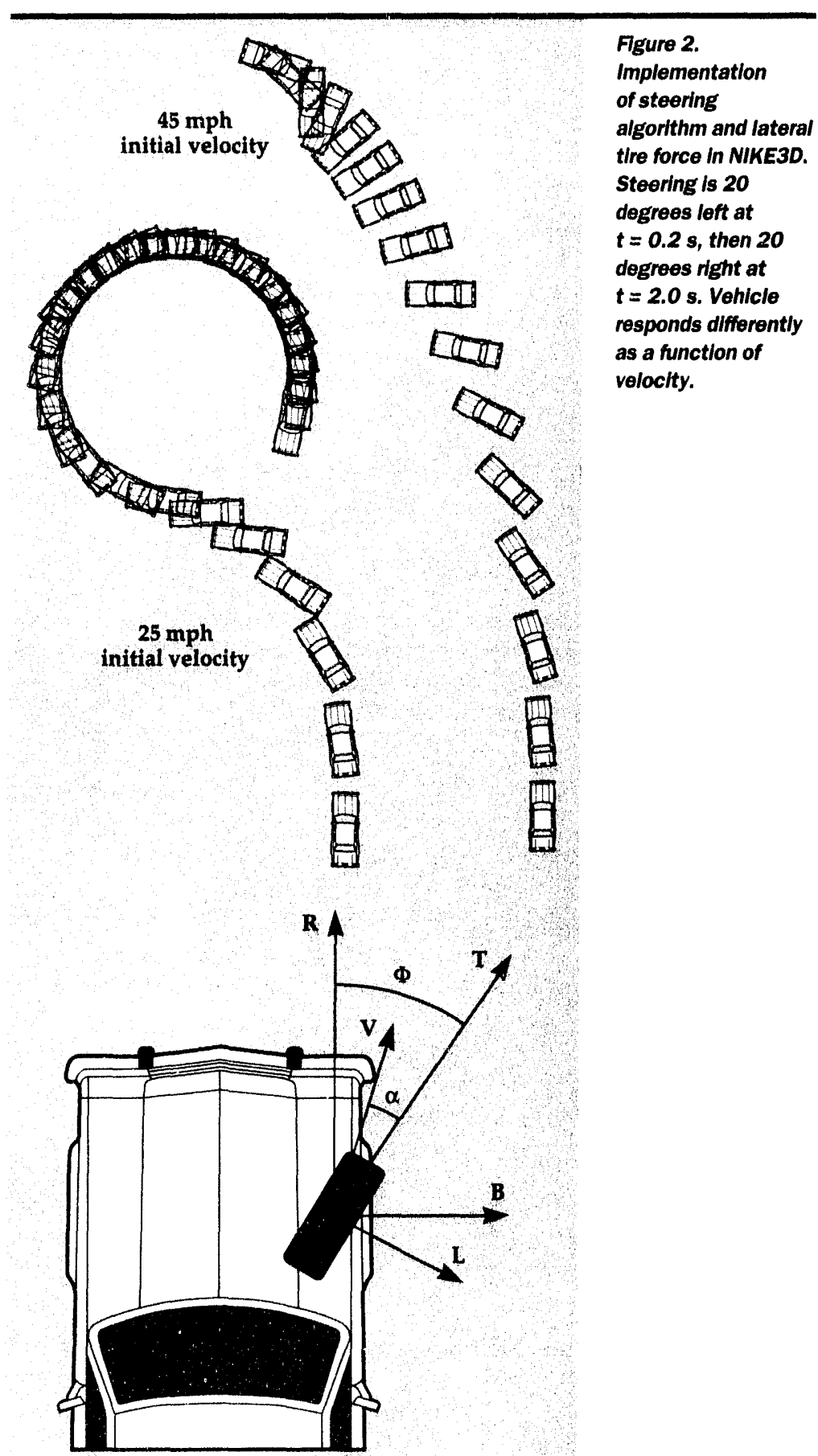

smaller components. This work was begun with an analysis of a rigid bogey developed through a collaboration between the California Department of Transportation (CalTrans) and the University of California Davis. The bogey has a crushable steel box-structure front end resembling a coarse honeycomb, as modeled with DYNA3D in Fig. 4. This analysis was run at slow velocities to approximate the static crush test conducted on the actual structure. The mesh was kept coarse in the spirit of workstation level 


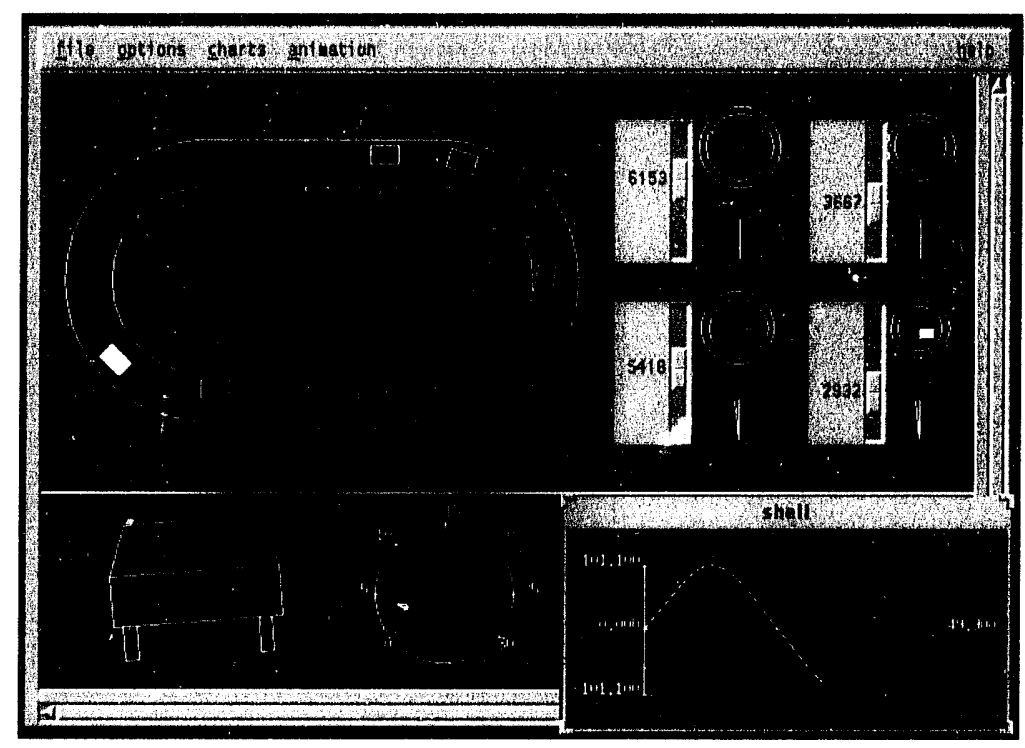

Figure 3. User interface for AUTOSLED handling program. Information includes position, speed, roll angle, original and current friction circles, normal and lateral tire loads, and slip angles.

Figure 4.

Workstation-level DYNA3D mesh of bogey front crush area on impacting rigid pole.

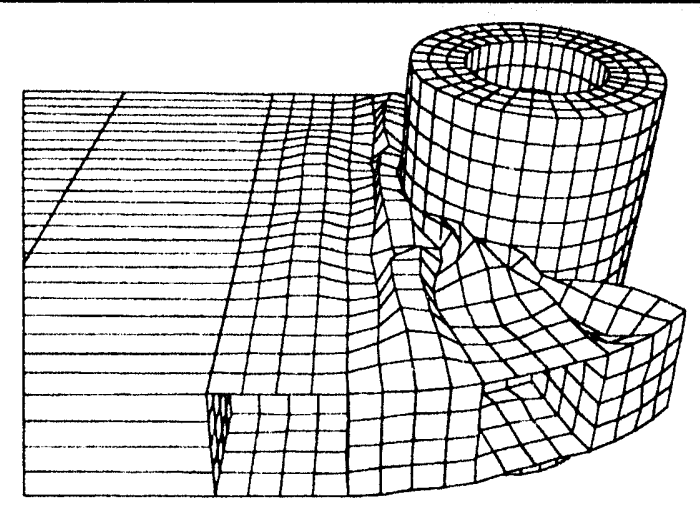

models, and load deflection was compared against the test data, as shown in Fig. 5. The first runs with DYNA3Dused an elastic perfect-plastic material model. This type of material behavior gives a numerically woll-posed problem that is mot tor dependent on the mesh size. However, the colculated load-deflection (DYNA-El-Pl line) is $t(x)$ stiff during early stages of the crushing process. Use of the atigmented forming Limit Diagram concept ${ }^{3}$ with rate-dependent flow and failure allow's a match to be achieved (DYNAFi.D) with the tent data. The effectiveness of adranced material models under development at I.L NI is demonstrated here for isotropic flow and failure. Related studies involve the integration of anisotropic flow and failure theories for amalesis of metallic and non-metallic materials, such as deep trawing stecls or chopped fiber componites. The type of simulation in Figs. 4 and 5 in neither predictive nor post-predictive,

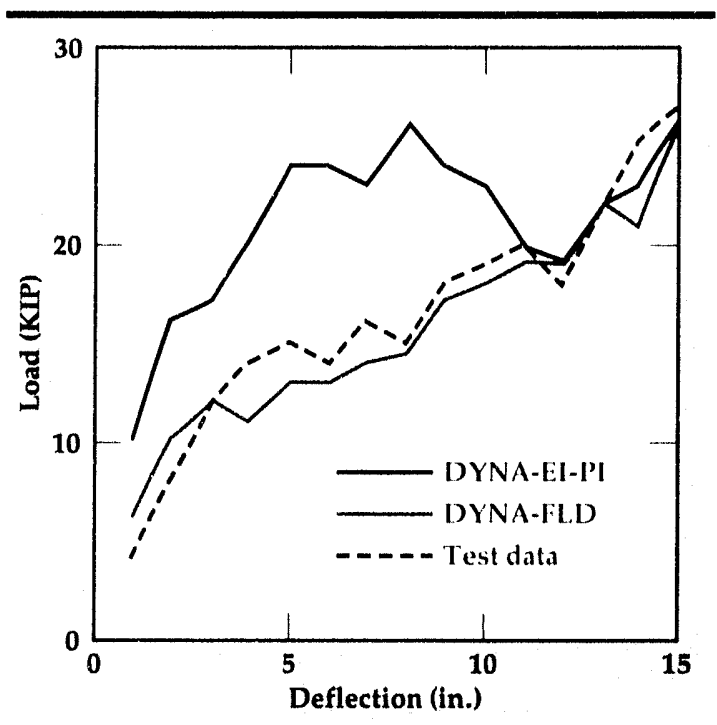

Figure 5. Load deflection for bogey crush into pole. Static test data matches DYNA3D if FLD failure model is used.

but is still of value in learning the techniques and meshing needed to match real tests.

Another matching exercise at the component level involved a small car hitting a modified bullnose median barrier. Crash test data for a Honda Civic hitting a modified bullnose median barrier head-on at 60 mph are documented by a report prepared by the Southwest Research Institute for the FHWA.t This test was chosen for simulation both because of the availability of test data and because damage to the car was relatively small, allowing a simple car model and a focus on barrier deformation. Since model size and run time were limited, and since many model parameters (especially material properties) had to be estimated, the model is simplified and contains many estimates of relevant parameters. Figure 6 shows the DYNA model and a sequence of plots as the car plows inte the barrier. The car was modeled as rigid. The barrier nose slit was not modeled; rather, the car was 'caught' by constraining the vertical displacements of the front bumper and the bottom edge of the bullnose. The zigzag cross section of the thrie-beam rail was approximated by a rectangular strip with the same moment of inertia and weight-perunit length as the thrie-beam. Since the deforming rail kinks at the posts where it is fastened, short lengths of thin, 12-gage strip were used near the posts to capture this kinking. The posts were modeled with tie-breaking slidelines, so that they broke off at ground level (as they did in the test), with a region of castic-plastio material just aboveground level 
to allow some energy dissipation during post breakage.

With the addition of self-contact and an approximation of the plastic hinge development at the posts, it is possible to match the vehicle trajuctory to the test data, as shown in Fig. 7. However, predictive or even post-predictive analysis will require further study of the thrie-beam and post components. We need to learn how to make the approximate, coarsi-mesh models shown here prorvide behavior consistent with more detailed models, without having to deal with increased computational requirements.

\section{Vehicle Models and Integrated Analysis}

A forerunner of analyses to follow was performed this year in a joint effort involving LLNL, the FHWA, and University of Alaska faculty. ${ }^{5}$ We developed a working model of a 1991 domestic sedan.

Our goal was to define the car in sufficient detail to capture its pre-crash, impact, and postcrash behaviors, and yet keep the model simple enough for analyses to be run overnight on a workstation. In the light pole impact example (Fig. 8), the car model is rigid material aft of the firewall. Underhood features are modeled as simple rigid bodies. The vehicle model consists of 20 parts, 2406 nodes with six degrees of freedom at each node, 10 beam elements, 1575 plate elements, and 224 solid elements. This is one example of problems we hope to eventually run routinely: large deformations of both vehicle and roadside features, with possible coupling to vehicle handling, in a workstation environment.

The model above was then used in post-predictive mode to demonstrate DYNA3D's crash modeling capabilities. These analytical predictions are compared with crash test results obtained from the National Highway Transportation Safety Administration, where this 1991 domestic sedan was impacted against a rigid wall at a velocity of $57.5 \mathrm{~km} / \mathrm{h}$. Although all major structural components of the car were accounted for, the soft crush characteristics of the bumper area were not accounted for in the vehicle model used here and in Fig. 8. To compensate for that, a clear distance of $0.5 \mathrm{~m}$ between the structural bumper and the rigid wall was allowed. Figure 9 compares DYNA3D prediction and crash test results of the time/acceleration history of the engine block (upper plot) and rear seat area (lower plot). (iven the coarse FEM of the model, the agreement is remarkably good.

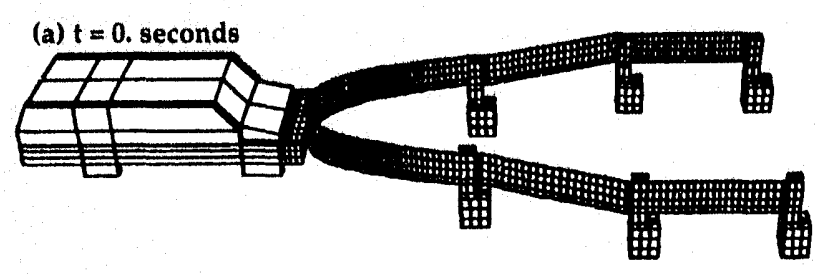

(b) $t=0.2$ seconds

(c) $t=0.4$ seconds

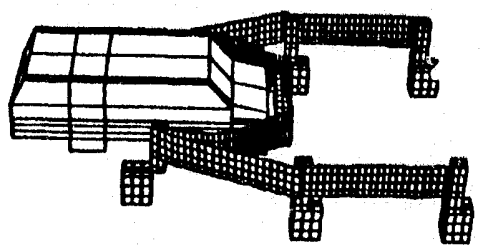

进

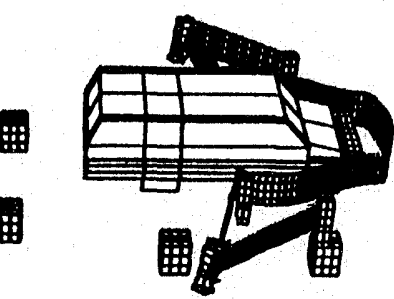

(d) $\mathrm{t}=0.6$ seconds

胟

(e) $\mathrm{t}=0.8$ seconds
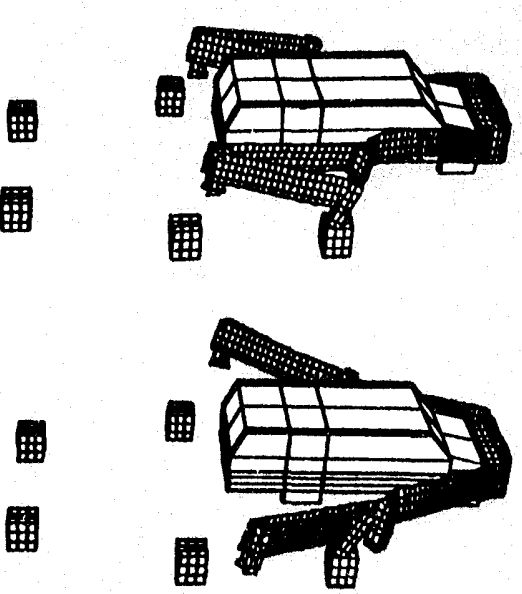

Figure 6. Time sequence of impact of simplified vehicle into modified bullnose barrier. Meshing is again at the workstation level.

\section{Test Data and Validation}

A vehicle model of a Ford Fairmont is being constructed. An instrumented test of this vehicle is planned to demonstrate the potential for and effectivene'ss of an integrated program of analysis, measurements, and vehicle testing. This may lead to further tests or parts of tests at LLNL.

\section{Future Work}

This year, we have demonstrated the effectiveness of integrated vehicle/barrier impact analysis at the workstation/FHWA/DOT level, and have identified the needs for additions and refinements 


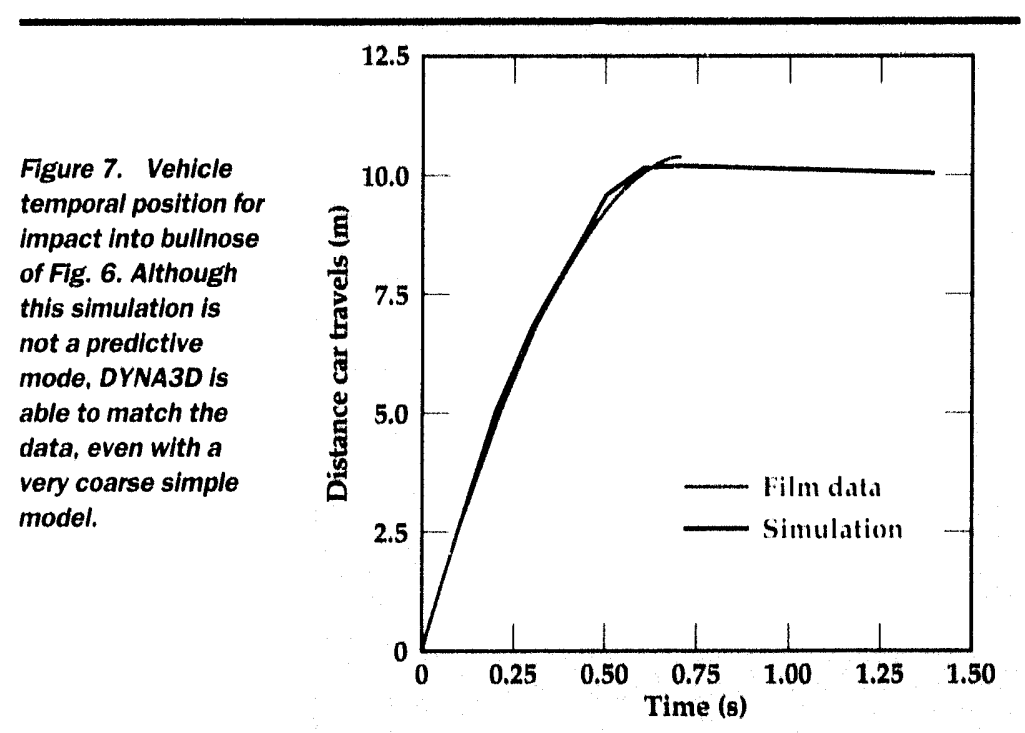

Figure 8. Time sequence of domestic sedan impacting luminaire support. Pole fallure is modeled with LLNL'S SAND technology.
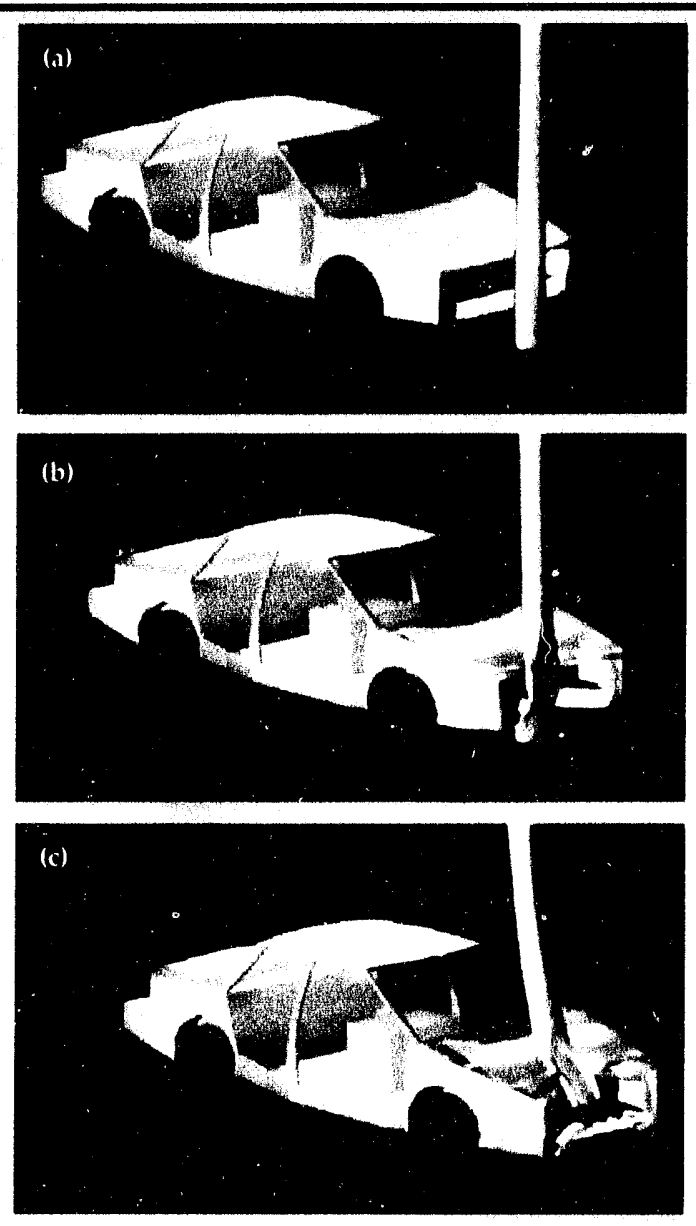

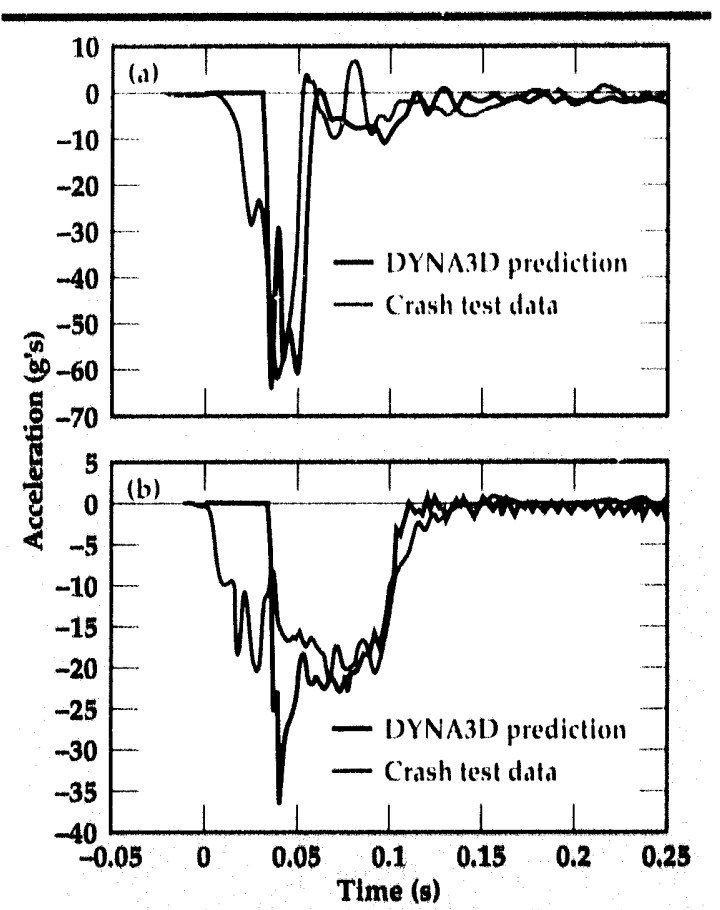

Figure 9. Acceleration history of vehicle model of Fg. 8 for a 30-mph rigid-wall impact. Comparison to NHTSA supplled data is done in post-predictive mode. Agreement is good for only a 2000-node vehicle.

leading to a complete package. Our goals for the future focus on the four technology areis established. We will work toward full linkage of the AUTOSLED RTH code to NIKE and DYNA, and development of compatible tire models for all the codes.

Continued study of both roadside and vehicle structural sections will continue at the component level toensure that model simplification is efficient yet accurate compared to more refined meshes. A more complete suite of vehicle models and roadside hardware will be developed, making use of material model improvements for flow and crush of aluminum and fiber composite materials, including features such as anisotropy, forming limit, and composite damage. These will be used in future lightweight designs such as Calstart's Neighborhood Electric Vehicle. We will continue the close integration of our analysis package with test data obtained at LLNL. and elsewhere.

\section{Acknowledgements}

The author wishes to acknowledge the many contributors to the TAHRS/VISTA program this year. (f) special note are the contributions of B.N. Maker (Fig. 2), D.D. Dirks and M.C. Seibol (Fig. 3), and S.J. Wineman (Figs. 4 and 5). The author appreciates the close cooperation of I'rof. A. Frank 
at the University of California Davis on the bogey analysis (Figs. 6 and 7), and of Prof. J. Wekezer of the University of Alaska on the domestic sedan model (Figs. 8 and 9 ).

1. R.G. Whirley, DYNA3D: A Nomlinera, Explicit, The'sDimensionnl Finite Elennent Code for Solit and Structumal Meihmics-Lliser Mammal, Lawrence Livermore National Laboratory, Livermore, California, UCRLMA-107254 (1991).

2. B.N. Maker, R.M. Ferencz, and J.O. Hallquist, NIKE.3D: A Nomline'nr, Implicit, Thre'-Dimensionnl Finite Eleme'nt Code for Solld and Stractural Mechmics-Llsicr Mammal, Lawrence Livermore National Laboratory, Livermore, California, UCRL-MA$105268(1991)$.
3. R.W. Logan, Implementation of a Pressurce and Rate' Dependent Forming-Limit Dingram Model into NIKE and DYNA, Lawrence Livermore National Laboratory, Livermore, Califormia, UCRL-ID-105760 (1992).

4. L. Meczkowski, A Thrie-Beann Bullnuse Medinn Trentment, U.S. Department of Transportation, Federal Highway Administration Publication Nos. FHWARD-88-004 and FHWA-RD-88-005 (1987).

5. J.W. Wekezer, M.S. Oskard, R.W. Logan, and E. Zywicz, "Vehicle Impact Simulation," 1. Transfortation Eng. (in press). 


\title{
EXTRANSYT: An Expert System for Advanced Traffic Management
}

\author{
Rowland R. Johnson \\ Engineering Research Division \\ Electronics Engineering
}

Coordination of traffic signal systems is carried out at present by a signal timing plan that uses a relatively primitive computer program, TRANSYT. To deal with the difficulties in using TRANSYT, our project is developing an expert system called EXTRANSYT that encodes the knowledge of an expert TRANSYT user. The project is a collaborative effort among (1) Lawrence Livermore National Laboratory, in the lead and providing the computers and computer science expertise; (2) the University of California Berkeley, Institute of Transportation Studies, providing the TRANSYT/traffic engineering expertise; and (3) the City of San Jose, California, Department of Streets and Traffic, providing the testbed for the system.

\section{Introduction}

Coordination of traffic signal systems is the primary means by which congestion, pollution, and fuel consumption caused by city traffic is reduced. A coordinated system can be either a single artery or a grid and typically consists of between 10 and 50 intersections. An intersection phase is the time duration for which the traffic lights at the intersection remain fixed. Each intersection has a controller that causes the intersection to cycle through its set of phases.

Coordination is achieved by the use of a signal timing plan wherein the controller at each intersection in the system has the same cycle length. That is, there is a background cycle during which each intersection cycles through each of its phases. The signal timing plan also specifies the offset for the beginning of each phase at each intersection.

One strategy for efficient coordination is achieved by good platoon progression. Platoon progression is the situation whereby a set of closely spaced vehicles (i.e., a platoon) progresses from intersection to intersection, and the platoon is given a green light as it arrives and passes through the intersection. Platoon progression also has the psychological benefit of drivers perceiving that they are moving faster through the system. Another strategy for efficient coordination is achieved by preventing multiple acceleration/de-acceleration cycles. For example, vehicles should be delayed (although the drivers perceive no apparent reason) until a platoon arrives that they can merge with. Usually travel time is the same, and a reduction in pollution and fuel consumption is realized because of the reduction in acceleration/de-acceleration cycles.

Signal timing plan design is usually done by using a computer program called TRANSYT that can (1) simulate the operation of a coordinated system, and (2) find the optimal signal timing plan based on some combination of congestion, pollution, and fuel consumption. Typically, a traffic

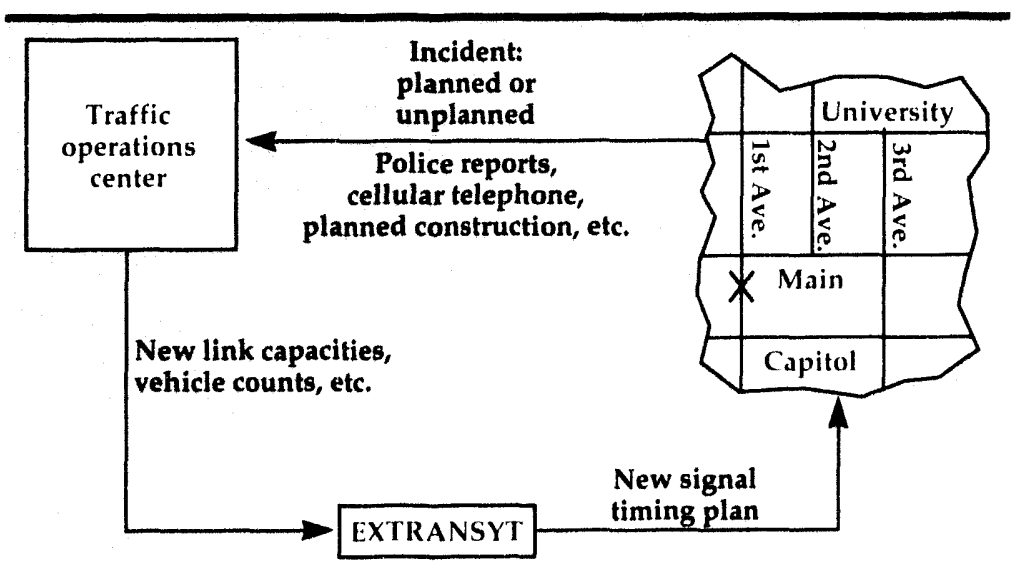

Figure 1. Real-time incident response. A traffic incident has occurred on a city street and has been reported to a central traffic operations facillty. Operations personnel determine the impact on vehicular flow capacities and vehicular flow demands. This information is then routed to EXTRANSYT, which quickly determines an appropriate signal timing plan and downloads it to the traffic light controllers. 
engineer will provide a description of a set of intersections and streets as well as traffic flow capacities and traffic flow requirements. The TRANSYT model is then calibrated against actual traffic flow conditions, followed by the search for the optimal signal timing plan.

TRANSYT has several limitations that are described below. However, the reality is that it is the only analysis tool of its kind and is likely to remain so for at least five years.

TRANSYT was originally developed in the 1960 's when input to computer programs consisted of a punched card deck, and the output device was a lineprinter. In response to the primitive nature of TRANSYT, several peripheral programs have been developed that make it easier to use TRANSYT. However, these efforts do not appear to be adequate since we have found that 30 to $50 \%$ of the 'fielded' signal timing plans have errors. Since the original development of TRANSYT, there have 'een several advances in intersection controller hardware that are not directly modeled by TRANSYT. However, it is possible for an expert user to derive useful results from TRANSYT about coordinated systems that use the newer controllers.

The difficulties in using TRANSYT results in an error-prone, lengthy process to develop a signal timing plan for a coordinated system. A traffic engineer not accustomed to using TRANSYT can require up to four months to develop a signal timing plan for a moderately complicated grid.

Furthermore, the resulting signal timing plan will often have errors that need to be 'tuned out' in the field, resulting in more time required and a sub-optimal signal timing plan.

\section{Progress}

To deal with the difficulties in using TRANSYT, our project is developing an expert system called EXTRANSYT that encodes the knowledge of an expert TRANSYT user. The project is a collaborative effort among (1) Lawrence Livermore National Laboratory (LLNL), in the lead and providing the computers and computer science expertise; (2) the University of California Berkeley, Institute of Transportation Studies, providing the TRANSYT/traffic engineering expertise; and (3) the City of San Jose, California, Department of Streets and Traffic, providing the testbed for the system.

The input to TRANSYT specifies a set of intersertions, streets connecting the'm, and the length of each street. It does not specify the location of each intersection. That is, the original Euclidean 2-space specification of the grid is reduced to an undirected graph. A particular undirected graph will have an infinite set of realizations in Euclidean 2-space. Therefore, it is impossible to present the traffic engineer with the two-dimensional (2-D) layout of the intersections and streets that yielded the TRANSYT input. This fact results in many input errors that are never discovered.

In practice, TRANSYT users usually use one of several intersection/street numbering schemes. EXTRANSYT uses heuristics to determine if such a scheme is being used and the Euclidean information derivable from it. Other heuristics about likely intersection/street configurations (e.g., a city street is unlikely to pass over another city street) are also used. As a result, EXTRANSYT is able to determine a likely 2-D layout. In practice, this layout is almost always close enough to the actual intersection/street configuration that the traffic engineer can easily discover input errors.

EXTRANSYT also uses another set of heuristics to discover probable errors not related to the geometry of the grid. For example, the situation where the speed limit in one direction on a street is not the same as the speed limit in the other direction on the same street is flagged as a probable error. As another example, many existing TRANSYT input sets have errors pertaining to the existence, non-existence, and direction of one-way streets. EXTRANSYT has proven to be very effective in finding these types of errors.

Future developments in EXTRANSYT will include heuristics to determine phase sequencing for each intersection. For example, should a particular approach be given the left turn before or after through traffic is allowed to move. Also included will be heuristics to determine which intersections should be in a coordinated system. Closely related to this will be heuristics to determine if an intersection should be fully actuated, semi-actuated, or non-actuated.

As described above, TRANSYT is used to design signal timing plans. Potentially, TRANSYT could also be used to respond to an incident occurring on a city street. As an example, consider an accident that causes the capacity of a street to be reduced and, further, that reduced capacity will exist for one hour. A modified signal timing plan based on the reduced capacity due to the accident would (1) take advantag z of reduced demand downstream of the accident, and (2) accommodate extra demand on the alternate routes chosen by drivers upstream of the accident. The problem with this approach is that the modified signal timing plan must be derived quickly. Typically, 15 
minutes are required to first download a signal timing plan and then switch to the new plan. In this example, to obtain 30 minutes of improved traffic flow, the modified signal timing plan must be derived in 15 minutes.

\section{Future Work}

The current version of EXTRANSYT has been installed at Department of Streets and Traffic in the City of San Jose, California for the purpose of developing a real-time incident response system. The deployed system in San Jose is linked to the development system at LLNL via high-speed modem lines. EXTRANSYT is being used to help analyze existing traffic situations in San Jose. This in turn is used to provide a better understanding of how to implement the heuristics described above. A real-time incident response version of EXTRANSYT will be operational in October 1993. 


\section{Odin: A HighPower, Underwater, Acoustic Transmitter for Surveillance Applications}

\author{
Terry R. Donich and \\ Scott W. McAllister \\ Defense Sciences Engineering Division
}

\author{
Charles S. Landram \\ Nuclear Test Engineering \\ Mechanical Engineering
}

The Odin project staff has performed an engineering assessment of an underwater acoustic projector using impulse-driven, split-ring-projector technology in an ocean surveillance, antisubmarine-warfare application. An Odin projector system could be engineered to meet the system requirements for output power and acoustic beam control; however, the final projector size raises serious issues about its compatibility with existing deployment platforms. This problem and the fact that the submarine threat has changed have led the project team to defer further work on this application and to focus on the air-deployable, impulse-driven projector being funded by the Navy.

\section{Introduction}

Split ring projectors (SRP) are acoustic transmitters for underwater use in active sonar systems to detect submarines. In FY-90, Lawrence Livermore National Laboratory (LLNL) developed the idea of using the combustion of chemical fuels to drive a SRP element. When a chemical fuel combusts inside the cylinder, the resulting inward pressure pulse drives the shell outward, loading strain energy into the split ring shell. The split ring shell 'rings' down, converting the strain energy into acoustic energy, as illustrated in Fig. 1. 'Impulsedriven split ring projector' is the phrase used to describe this system.

The chemical fuel-driven SRP overcomes the acoustic power limitation encountered when piezoelectric cerandics drive the split ring shell. At LLNL, our capabilities in numerical modeling of combustion and detonation and in structural modeling give us a unique capability to assess the feasibility of impulse-driven SRP's. ${ }^{1}$

In FY-92, we were funded to assess the feasibility of the impulse-driven SRP concept, scaled to a ship-towed surveillance system, as illustrated in Fig. 2. The hypothesis put forth in the reviews was that impulse-driven SRP technology could create the acoustic power required by the surveillance community in a reasonably sized, hydrodynamic package that could be towed with greater ease than the existing projector arrays. The basis for the hypothesis was twofold: (1) package size would be reduced, since the direct conversion of chemical energy into strain energy was more efficient than converting the chemical energy into electricity, conditioning that electricity, and creating strain energy with magnetostrictive or piezoelectric materials; (2) the SRP, being long and slender, provided a more hydrodynamic shape than other piezoelectric or magnetostrictive projectors.

\section{Progress}

This project comprised four tasks: (1) the enhancement of our fluid-loaded SRP codes, SOFA ${ }^{2}$ for the frequency domain and SOTA ${ }^{3}$ for the time domain; (2) a parameter study of surveillance-scale

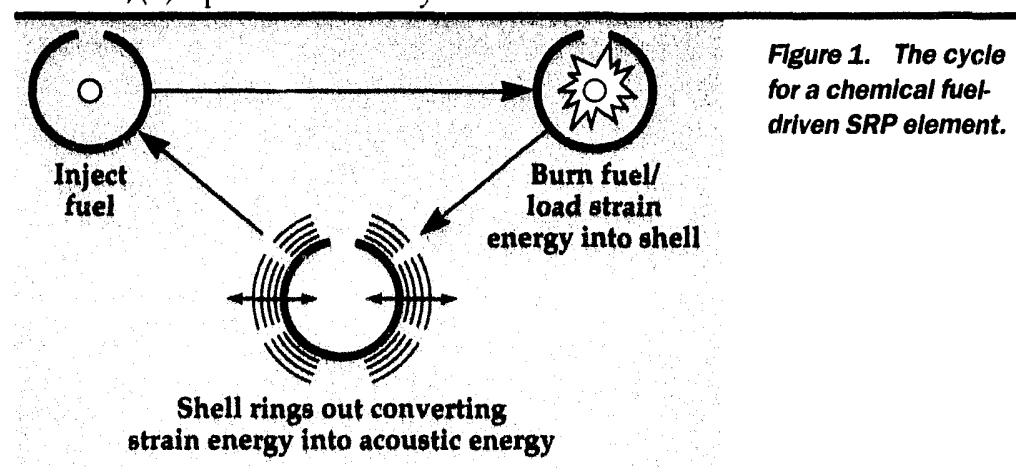


Figure 2. Configura tion of Odin projector and SWATH/SUR.

TASS.

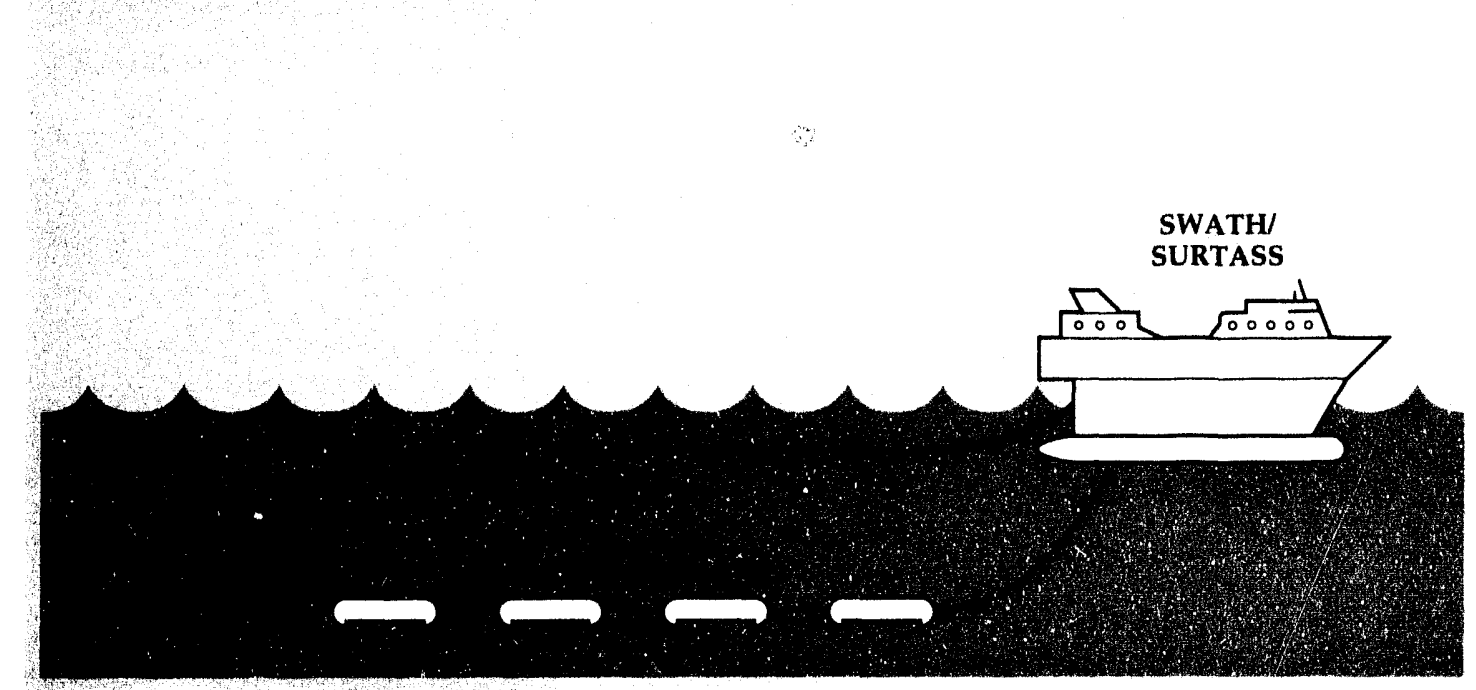

SRP's; (3) an assessment of the feasibility of the projector parameters in an actual application; and (4) marketing activities for this project and related projects.

Our parameter study yielded the following results:

(1) The optimal radius at $20 \mathrm{~Hz}$ is $1 \mathrm{~m}$; the corresponding shell thickness for this frequency is $24.4 \mathrm{~cm}$. The shell material is steel.

(2) The chemical-to-acoustic energy conversion efficiency is low $(\approx 1.5 \%$ for $\mathrm{L}=20 \mathrm{~m})$.

(3) Acoustic powers of $\approx 363 \mathrm{~kW}$ or $226.4 \mathrm{~dB}$ are attainable with an input of $310 \mathrm{MJ}$ of chemical energy. The peak stress is within the elastic range for high quality steels.

(4) The projector acoustic output has the temporal characteristic of $P_{n}, e^{-e x}$ sinct. Our experimentally validated analytical model predicts $\alpha=0.095 \mathrm{~s}^{-1}$ for this shell radius and projector frequency.

From our engineering assessment, ${ }^{4}$ we determined that in an array of these large SRP's, the $2 \sigma$ individual projector timing specification must be $0.005 \mathrm{~s}$. This specification is realizable from an engineering point of view. It will take approximately $60 \mathrm{~s}$ to recycle a projector after it fires. This time includes the time to purge the exhaust and reload the fuel/oxidizer for the next shot.

A five-element projector array with a per element power of $226.4 \mathrm{~dB}$ will enable detection ranges in excess of 140 nautical miles. 5

Five 2-m-dia-x-20-m-long projectors are massive enough to question the ability of existing platforms to recover such an array.

Our marketing activities are influenced by the status of the Navy surveillance community. Redefinitions of their mission include the transition of the surveillance enviromment from deep water to shaliow water; and the transition of surveillance platforms from vulnerable ships to air-deployable disposablesystems.

The Navy is not able to fund this project in FY-93.

LLNL staff were asked to witness a Navy test series off San Clemente lsland to assess the performance of the current generation of surveillance projector technology." This information has been used to submit additional white papers for reimbursable work for the Navy.

The Office of Naval Research (ONR) has expressed interest in the techniques used in SOFA and SOTA, our two fluid-coupled split-ring modeling codes. A white paper has been prepared, on the basis of the ONR interest, to assess some of the fundamental questions that arise when modeling the acoustic radiation from a complex stiffened structure?

In summary, although the Odin project, $r$ concept is feasible from an engineering point of view, a large funded project is precluded because of the major redefinition of the missions of surveillance communities. However, our marketing has uncovered other potential funding sources for related projects.

\section{Acknowledgements}

We thank the staff of LLN N's Military Applications and Advanced Conventional Weapon Systems for their support. (Our thanks also go to Tom Reitter for his numerical computations, using C ALI: to determine the pressure time histories generated internal to an underwater cylinder by an explosive charge; to Ensign Hal Perdew for his work in the 
systems studies of SRP arrays; to Barry Bowman for marketing assistance; to S. Christian Simonson, Robert Tipton, and Rich Couch for computations; to Kent Lewis for mode conversion; and to Clark Sauers who formulated the equation of state for non-explosive energetic material.

1. C.S. Landram, "SOFA," 1991-1992.

2. C.S. Landram, "SOTA," 1991-1992.

3. T.A. Reitter, "CALE Calculations of Small-Charge Explosions in Underwater Pipes," TF92-34, April 2,1992 .
4. H.C. Perdew, "Timing Requirements on Split Ring Projector Arrays," August 1992

5. H.G. Perdew, "Performance Assessment of Split Ring Projector Arrays in Shallow Water," September 1992.

6. S.W.McAllister "Lessons Learned From NCCOSC, NRAD Tests of $9 / 16 / 92$ and 9/17/92," September 18,1992

7. C.S. Landram, "ONR Proposal on Mode Conversion," TF-92-76, September 21, 1992.

8. S.W. McAllister, "Electrically Initiated - Frequency Dispersive Sources, A Requirements Document," October 1, 1992. 


\section{Passive Seismic Reservoir Monitoring: Signal Processing Innovations}

\section{David B. Harris and \\ Robert J. Sherwood}

Engineering Research Division

Electronics Engineering

\author{
Stephen P. Jarpe \\ Earth Sciences Department
}

\section{David C. DeMlartini}

Shell Development Company

Houston, Texas

We have extended our matched field processing capability in mapping acoustic emissions associated with hydraulic fracturing. In our new approach, we generate elastic matching fields for a range of source types, and match the best linear combination of these fields, against the observed data. We have begun work with Shell Development Company, applying our methods to data from their monitoring wells.

\section{Irtroduction}

Hydraulic fracturing is a widely used well completion technique for enhancing the recovery of gas and oil in low-permeability formations. Hydraulic fracturing consists of pumping fluids into a well under high pressure (1000 to 5000 psi) to wedge open and extend a fracture into the producing formation. The fracture acts as a conduit for gas and oil to flow back to the well, significantly increasing communication with larger volumes of the producing formation. While typical treatment costs exceed $\$ 100,000$ per well, hydraulic fracturing may double or triple production. Such returns justify extensive use of the technique. In the interval from 1949 to 1981 , more than 800,000 treatments were completed. ${ }^{\prime}$ In tight gas sands and diatomite oil reservoirs, ${ }^{2}$ virtually all new wells are hydraulically fractured.

Field engineers need diagnostics for the height, length, and orientation of fractures to design the proper spacing of wells in the field and to design individual fracture treatments. The diagnostics must be inexpensive (10\% of treatment cost), fast, and reliable. Diagnostics that are available in a few hours can be used to plan successive stages of a multistage fracturing operation in a single well; diagnostics that take minutes could be used in real-time controls of pumping rates and fluid composition.

The best diagnostics that fully map a fracture use transient microseismic signals emitted from micro-fracture events along the fracture surface. 3,4 These signals are detected by sensors placed in adjacent monitoring wells or in the treatment well. The arrival times of the signals are measured (usually manually), then used to triangulate the sites of emission. The 'cloud' of locations for several hundred discrete emissions delineates the fracture. This method is slow due to the need for manual picking of arrival times, and has potentially limited application when an insufficient number of high signal-to-m sise ratio transient signals are detectable.

We have adapted matched-field processing methods to the problem of imaging fractures, using continuous microseismic emissions.

\section{Progress}

In FY-92, we extended our earlier results, ${ }^{5}$ which used an acoustic model for propagation, to the 


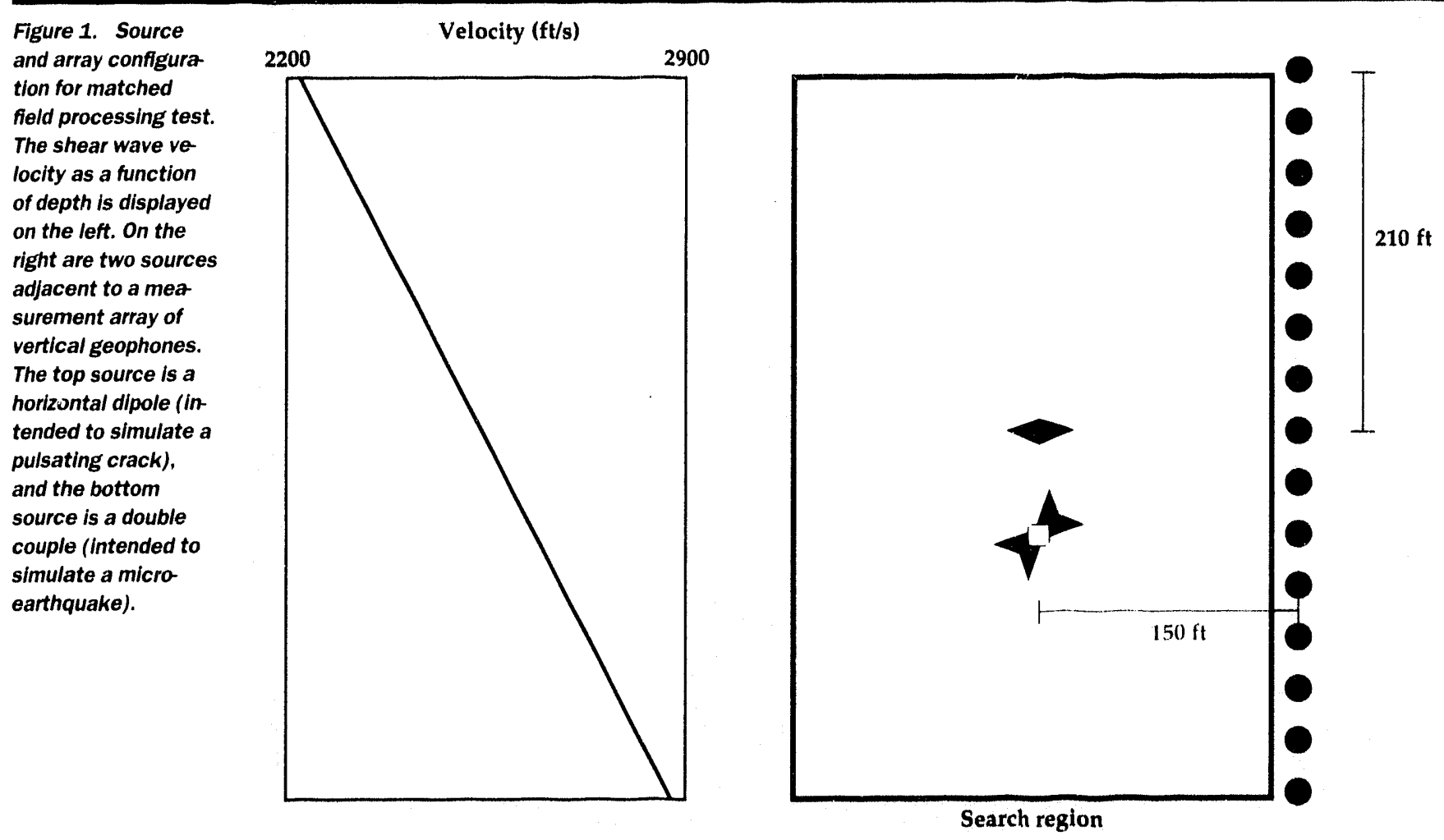

case of full elastic propagation. We have developed two elastic field simulators; one to produce test data, and another that is a highly efficient narrowband code to generate matching fields for the array of sensers. The latter code involves innovations in paraxial wave field extrapolation," that have potential application to oil prospecting and ocean acoustic modeling. We hare also develupect a matched field processor with the ability to match a wide range of source types. Hydraulic fracture microseismic sources may come in a variety of forms, such as an opening crack caused by pumping, or microearthquake's caused by slip between adjacent blecks in the prestressed medium.

We simulated these two types of sources for the source and sensor configuration, shown in Fig. 1. for a medium intended to approximate the contitions in the Shell Belridge oil field.' Figure 1 show's a vertical array of vertical-axis geophones in a monitor well, and two simulated sources 15 () feet away. The array has 15 geophones spaced at 3()-ft intervals, which is similar to the Shell Belridge sensor configuration. The velecity structure is nonuniform, consisting of a gradient with shear wave speeds ranging from 22()$(0 \mathrm{ft} / \mathrm{s} t$.) $2(x)() \mathrm{ft} / \mathrm{s}$ over the aperture ef the array.

The fields radiated by the two source types are markedly different and require a new processing strategy for situations where the source type is unknown. Figure 2 shows the fields generated by the opening crack and the slip type sources. The two sources radiate energy away from the source location with very different patterns as a function of direction. The signals received by the array are correspondingly unique. This presents a problem if the matching field is not chosen appropriately, as shown in Fig. 3. The first two reconstructions of the two-source test case are reconstructed with theoretical fields corresponding to a single source type. In both cases, one of the sources is missing in the reconstruction.

Our response to this problem was to develop a modification of the matched field processing approach, which we call multiple-field matching (MMFI'). In this approach, we generate matching fields for a range of possible source types, and match the best linear combination of these fields point for point in the search regions, against the observed data. The result of MMl:P' for our test cisce, shown in Fig. 3, is an image containing both sourectypes.

\section{Future Work}

We have entered into an agreement with shell Development Company to apply matched field 


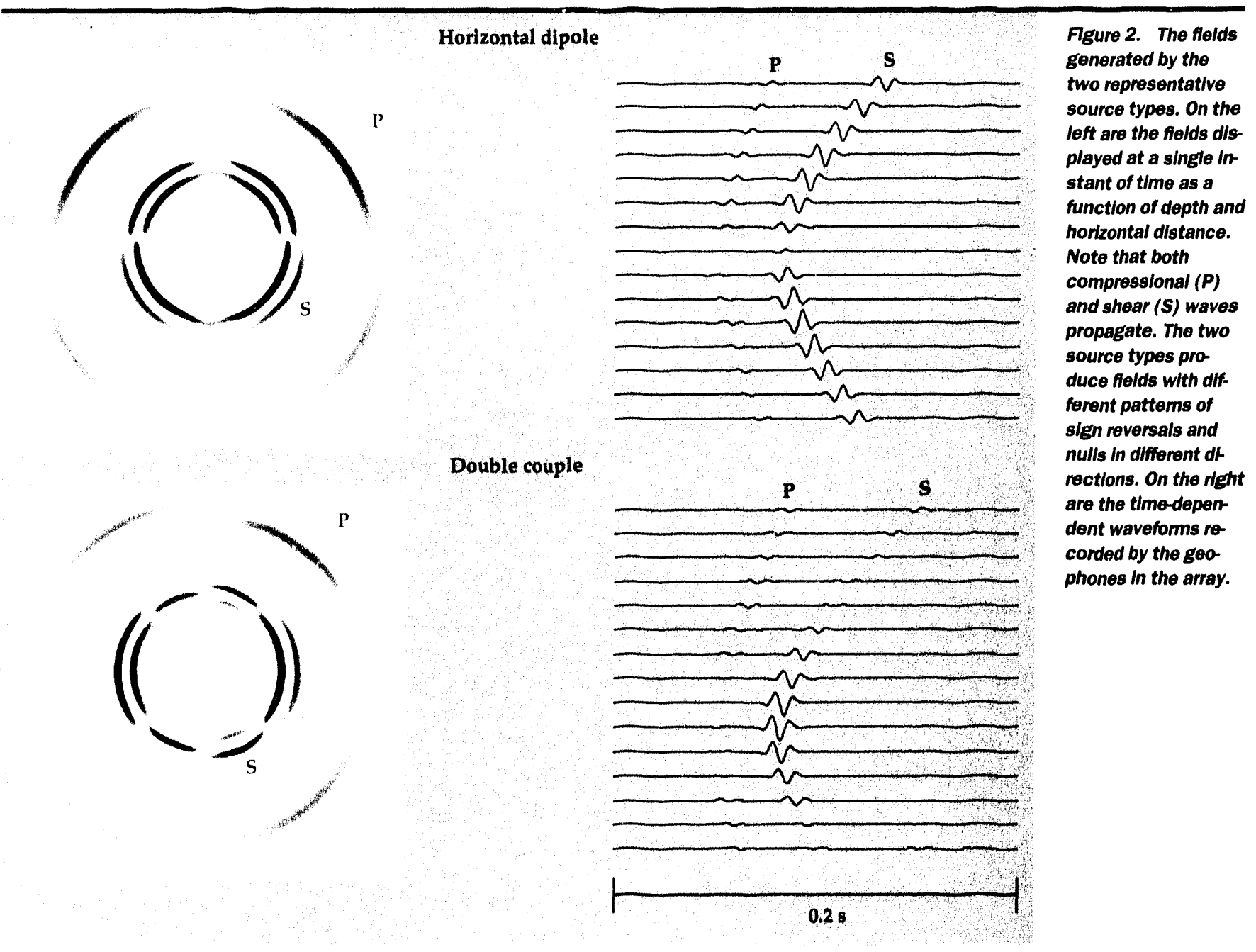

(a)

(b)

(c)

Figure 3. Three reconstructions of the source distribution made from the sum of the two sources shown in Fg. 2. The reconstructions are for the search region outlined in Fg. 1. Reconstruction (b) uses a double couple field, and misses the horlzontal dipole source. Reconstruction (c) is the MMFP reconstruction that uses a best Iinear combination of both fields point for point in the search region, and picks, 1 both sources.

processing methods to their Belridge hydraulic fracture data set. ${ }^{7}$ The Shell data set is the best. available data for testing hydraulic fracture imaging diagnostics. It includes two multi-stage fracture operations recorded by three monitor wells. The vertical geophone sensors were grouted into the wells, largely suppressing the tube waves that confound hydrophone recordings in fluid-filled monitor wells. Preliminary analysis of the data has shown us the necessity of using the multiple field extension of matched field processing with real data. We anticipate that our analysis will providea definitive test of the value of matched field processing in the coming year. 
1. B. Waters, I. Pet. Tieh, 1416 (August 1981).

2. "Frac Attack," ChermwWild Spring/Summer, 24 (1991).

3. J. Fix. R. Adtair, T. Fisher, K. Mahrer, C. Mulcahy, B. Myers, J. Swanson, and J. Woerpel, Denelopme'n of Micruse'ismic Methends To Determine Hydroulic Frmeture Dimn'nsions, Teledyne Geotech, Garland, Texas, Technical Report No. 89-(116(1989).

4. B. Thorne and H. Morris, SPE Form. Evol, 711 (I)ecember 1988).
5. D. Harris, R. Sherwoed, S. Jarpe, and P. Harben, Mapping Acoustic Emissions from Hydranlic Fracture Trentments Using Collerent Array Processing: Comcipt, Lawrence Livermore National Laboratory, Livermore, California, UCRL-ID-108262(1991).

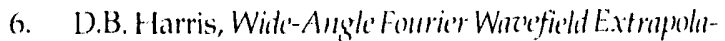
fors for Laterally Heterogenens Mertia, in preparation.

7. H. Vinegar,I?. Wills, D. DeMartini,J. Shiyapobersky, W. Deeg, R. Adair, J. Woerpel, J. Fix, and G. Sorrels, 1. Pet. T'i'h, 44 (1) 28 (January 1992). 


\title{
Paste Extrudable Explosive Aft Charge for Multi-Stage Munitions
}

\author{
Douglas R. Faux and \\ Russell W. Rosinsky \\ Nuclear Eiplosizes Engineering \\ Mechanical Engineering
}

Our development project for a paste extrudable explosive (PEX) aft charge is a multi-year effort with the goal of demonstric ing the technology in a multi-stage munition. In FY-92, we studied PEX borehole fill characteristics and PEX initiation schemes.

\section{Introduction}

Multi-stage conventional munitions typically have a two-stage warhead: a forward-shaped charge that produces a borehole in the target, and an aft charge that enters the borehole and then detonates, destroying the target. The aft charge is usually a steel-encased explosive that either enters the borehole by its own kinetic energy or is 'driven' into the borehole by a rocket or velocity augmenter.

To increase the versatility and reduce the weight of a portable, multi-stage munition, a paste extrudable explosive (PEX) aft charge that injects PEX into the borehole formed by the forward charge replaces the steel-encased aft charge. The PEX aft charge can be used with a smaller borehole and provides greater coupling of the explosive with the target.

\section{Progress}

The PEX Aft Charge project is a multi-year effort with the goal of demonstrating the technology in a multi-stage munition.

The PEX aft charge is a proposed, pre-planned product improvement for the penetration augmented munition (PAM) currently being developed for U.S. Special Operations forces and future multi-stage munitions. Figure 1 illustrates a conceptual drawing of a standoff destruct munition (SODM, or 'flying PAM') using a PEX aft charge.

Our FY-92 development work on the PEX aft charge involved two areas: PEX borehole fill characteristics and PEX initiation schemes. Computer modeling of the PEX extrusion through a nozzle and of the borehole fill process has been completed and will be validated by forthooming tests.

The two-dimensional hydrodynamic code CALE has been used to model the PEX borehole fill process (Fig. 2). The complete simulation required the coupling of a DYNA2D analysis of the PEX extrusion through a nozzle, to the CALE analysis of a borehole fill.

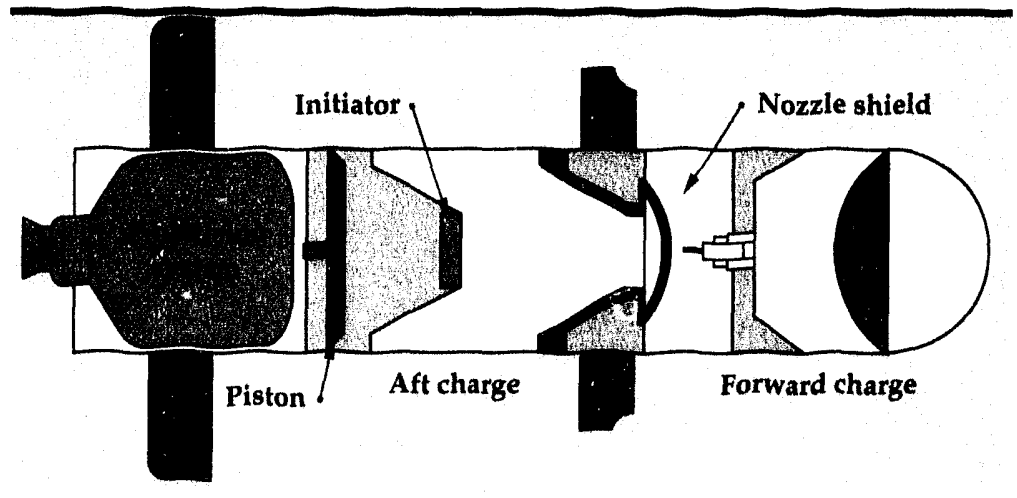

Figure 1. Conceptual sketch of a SODM with a PEX aft charge.

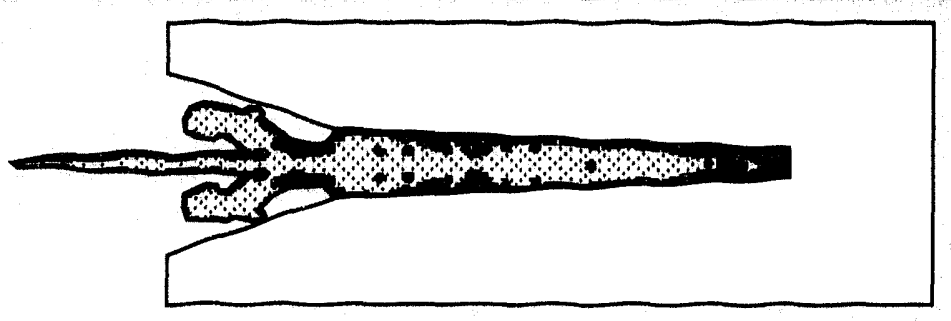

Figure 2. CALE Simulation of a PEX borehole fill. 


\section{Future Work}

Four tests are scheduled: two tests will evaluate PEX flow characteristics during borchole fill aid potential sympathetic detonation of the PEX; tivo tests will investigate PEX initiation schemes.
The first initiation scheme involves the use of a detonation chord and carrier vane to pull the detonation chord into the borehole with the PEX; the second initiation scheme involves the use of three chemically delayed detomators that will flow with the PEX into the borehole. 


\title{
A Continuum Model for Reinforced Concrete at High Pressures and Strain Rates
}

\author{
Kurt H. Sinz \\ Earth Sciences Department
}

We are studying the behavior of concrete at high pressures $(200 \mathrm{~kb})$ and strain rates $\left.(10)^{4} / \mathrm{s}\right)$ and report on a computer model used for this purpose. Applications include a predictive capability for the damage done to concrete when it is subjected to attack by demolition munitions or penetrators.

\section{Introduction}

Concrete is one of the most common building materials in the world. In 1992, the U.S. alone used an estimated 265 million cubic yards. ${ }^{1}$ Consequently, the need arises for occasional demolition or perhaps even destruction, such as in the event of armed conflict. Recent advances in small-scale munitions make it possible to consider the effects of a successful point attack against concrete even when it contains heavy steel reinforcement ('rebar'), as in bridge piers or bunkers. The damage mechanism is very different from that in seismic events or in ground shocks induced by nuclear explosions where damage results from large-scale flexure and fracture or rebar pull-out.

\section{Payoff of Predicting Concrete Damage}

To date, no computer model exists that can predict the damage envelope in concrete resulting from an interaction with a demolition munition or a penetrator. A calculational model that predicts the damage done to concrete subjected to point attack is highly desirable for a number of reasons. With the help of such a model, experiments could be more effectively designed to yield specific information, thus increasing the 'leverage' of experiments that are performed. Aspects of experiments and tolerances of design that are not laboratory perfect' could be evaluated by computer. This might include non-ideal standoffs, oblique angles of incidence, and structural peculiarities. This capability in turn would permit the design of a new munition to be more effectively optimized, and the survivability of penetrators could be calculated. Development time of new munitions would be shortened and would require fewer experiments. The resulting cost savings and product improvements are obvious.

\section{Problem}

The problem we pose is to develop a continuum model for concrete that explains the results of experiments performed for the penetration augmented munition (PAM) program. A rebar-cutting charge for the PAM has been designed to specifically attack concrete and to cut near-surface rebar up to No. 11 in size. ${ }^{2}$ The minimum diameter of this size rebar (when ignoring any ribbing) is between 3.3 and $3.4 \mathrm{~cm}$. Data from rebar-cutter tests exist that do not seem to be obscured by complicated hydrodynamic motion. Inhomogeneities are small compared to the effects of scale, and rebar spacing is of the order of the damage scale. The configuration is therefore amenable to analysis by a two-dimensional (2-D) Lagrangian continuum code such as DYNA, ${ }^{3}$ and rebar-cutter experiments are especially pertinent to this effort from the standpoint of providing data as well as filling a need.

\section{Concrete Properties}

To construct a continuum model, we need to know available properties of concrete. A great deal of attention has been devoted to the understanding of 


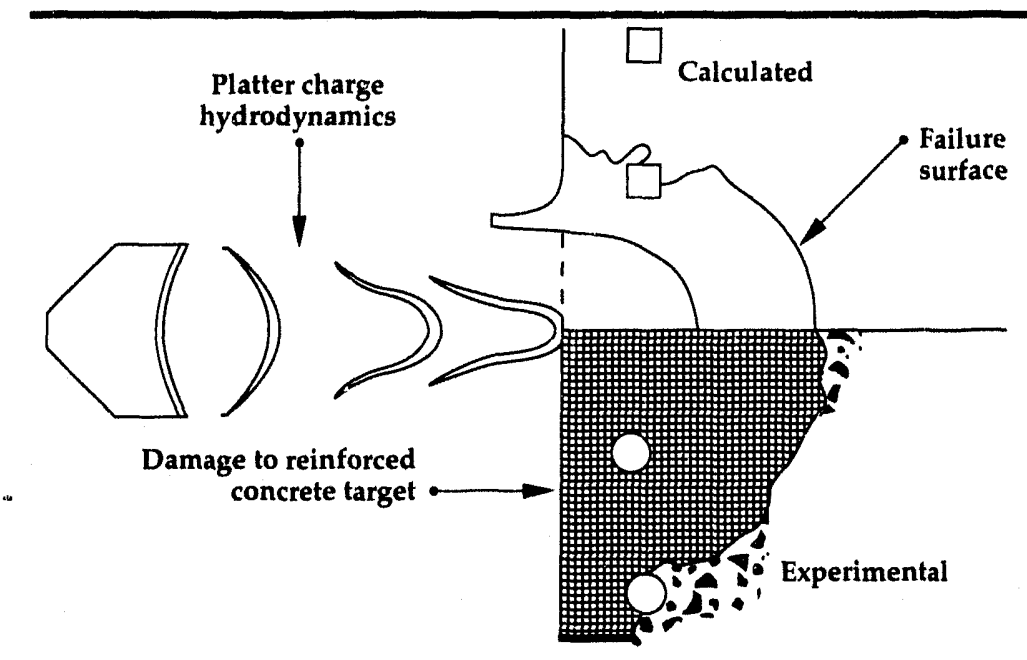

Figure 1. Overlay of calculation and actual hole profile. The material boundaries show the concrete surface after crush and the limit to which material is failed. All the original material is still in the problem and no excavation or 'throw-out' has occurred. The rebar is approximiated as rings of square cross section with the central rebar omitted. borehole. The effects of tensile failure are discussed below.

The presence of rebar does not seem to be important to the damage. The mechanism for forming the hole is not so much that of excavating material but rather failing material without a lot of hydrodynamic motion. The majority of the damage by volume results from shear failure. The strain rates that develop in the concrete when attacked by demolition munition reach about $10^{4} / \mathrm{s}$ with pressures of about $200 \mathrm{~kb}$. The calculations were done in KDYNA, ${ }^{10}$ which is a minor variant of the DYNA code. ${ }^{3}$ in that it includes a material model from TENSOR. "The problem was much simplified by replacing the actual impacting metal from the rebar-cutter charge as a time- and space-dependent pressure profile on the surface of the concrete. The pressure history was obtained using CALE when the charge was acting against aluminum. ${ }^{12}$ Comparisons were made using aluminum in DYNA to assure that resulting pressure distributions in the aluminum were properly calculated in comparison to CALE. The charge was in fact well represented by the pressure-time history on the surface. The explicit absence of the charge greatly simplified our calculations and made them more suitable to treatment by a Lagrangian code.

Using our model for concrete (discussed below), we calculated the effect of a rebar-cutting charge against plain, non-reinforced concrete. Figure 1 does include an annular approximation to the rebar as an illustration of the results. All the original material still resides in the problem. The surface 'dent' results from pore crush and displacing some material into the crater lip. Another boundary is the limit of material failure that results from shear failure. This is considered to be the damage envelope, and failed material is assumed to either fall out of the hole or to vacate the region by other mechanisms such as interaction with explosive gases. A comparison is shown with an experimentally obtained hole. It is apparent that the hole depth as defined in the calculation is in excellent agreement with the experiment.

We took some pains to try to explain why the calculated hole width is much less than the experiments indicate (Fig. 1). Accuracy in the definition of the applied pressure profile in time and space was eliminated as a possible cause. Currently, we identify three possible causes. The first is related to the zoning that the Lagrangian code DYNA generates as the crater begins to form. Zones that are long in the direction parallel to the crater wall cannot accurately transmit a signal that emanates 
from the crater bottom and travels along the crater wall. Furthermore, it appears this signal travels though material that is already dynamically failed and therefore is not reliably characterized. There is some indication that if the signal were well resolved by the zoning, that tensile failure would matter somewhat in this region. We should note, however, that the calculated bore hole is large enough to admit follow-through charges of current design so that the resolution of these questions, while highly desirable, may possibly not be central to our first objective. It is most interesting that tensile stresses were not found to matter anywhere in the problem except possibly right on the crater wall and then parallel to it. Reflections from the experimental sample block's boundary did not contribute appreciable reflections and tensile waves for two apparent reasons. The first reason is that the porosity in the concrete is a good shock attenuator and only low-level signals reach the boundary. The second reason is that a release from the target surface follows the main shock and contributes to its decay from behind.

Since we are limited by the constraint that DYNA is a 2-D code, two different attempts were made to estimate the importance of the rebar. In the first attempt, the rebar directly under the impact area was ignored, and the remaining rebars were represented as rings with radii of the rebar spacing (Fig. 1). The rebar was hardly displaced and had virtually no effect on the failure envelope. This result stems from the porosity-induced attenuation in the concrete and is consistent with experimental observations where the rebar is linear as opposed to circular. In the second estimate, the rebar was represented as a solid slab of steel, three centimeters thick, which was backed by concrete and covered with $6 \mathrm{~cm}$ of concrete (Fig. 2). Plastic strains of $10 \%$ in the steel were observed to a radius of about $3 \mathrm{~cm}$. This result makes it plausible that a three-dimensional calculation would give sorne amount of gap in the rebar using our current model and its parameters. This, of course, is the objective of the rebar cutter.

Another interesting phenomenon was observed in this latter calculation. The concrete cover of the rebar absorbed sufficient momentum in the radial direction to continue to 'peel' off the rebar (the solid slab of steel). The occurrence of this phenomenon distinguished this calculation from those without any steel. We assumed zero bonding strength between the steel and the concrete. It seems plausible that this general phenomenology of the concrete cover peeling at a plane of weakened bonding may explain why all the concrete cover seems to blow or crack off when a PAM is tested against a sample block of reinforced concrete.

\section{Model}

We now give a brief review of the model we use. The model combines the effects of pore crush, shear failure, and tensile failure. The aspect of pore crush is represented by a hysteresis model with a tensorial model for shear failure. This basic model has been used in TENSOR ${ }^{4}$ for a number of years to calculate the behavior of earth materials when subjected to high shock pressures. The model, with some improvements, ${ }^{13}$ has been carried forward to KDYNA. " Numerical data for the model are obtained from Gregson's Hugoniot, which also accounts for the pore crush in loading. The pressure at which total crush of the porosity occurs is assumed to be $100 \mathrm{~kb}$. There is a perhaps fortuitous match between Gregson's Hugoniot and the Hugoniot for fused silica ( $\mathrm{SiO}_{2}$ or Dynasil) at the high-pressure end. We follow this suggestion and assume the Hugoniot for fused quartz to be applicable to dynamically fully crushed (pulverized) concrete. This assumption seems reasonable, since concrete is mostly quartz.

The pore crush model works by letting a piece of the material load along the Hugoniot. Upon release, the unloading does not simply reverse the loading path; instead, hysteresis is approximated by interpolating a release path from the Hugoniot between the elastic portion of the loading curve and the Hugoniot for fully crushed material. The

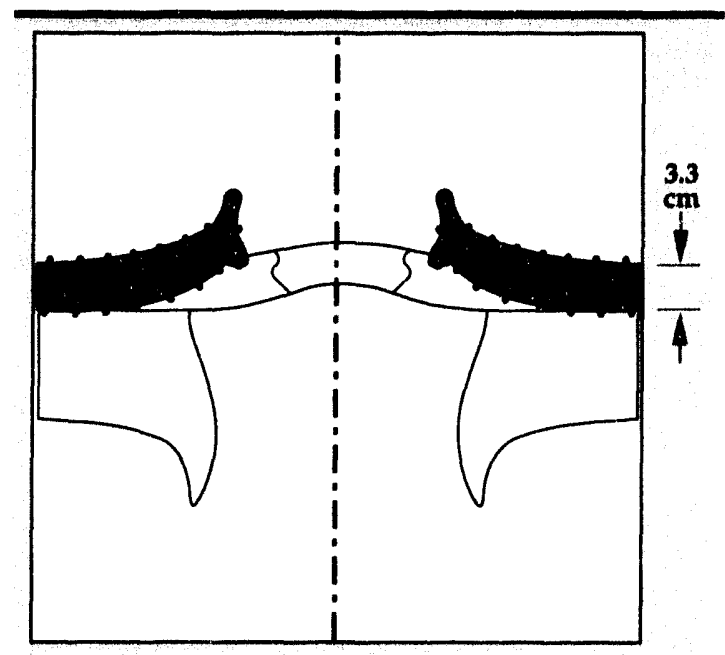

Figure 2. Overlay of rebar cut by the rebar-cutter charge and a calculation. The scales are only approximately the same. In the calculation, the rebar is approximated as a sof id slab of steel. The lines of $10 \%$ plastic strain in the steel are shown as a suggestion where the limit of calculated fail ure in the steel might be. 
hysteresis is of course a representation of the pore crush that is fully present and accounted for in the Hugoniot. At any point in this space, the pertinent bulk modulus is inferred. The resulting bulk modulus is thus a function of pressure that is related to strain rates in shock regions. Poisson's ratio is obtained as an extrapolation of Tang's work ${ }^{8}$ so that the shear modulus is also defined.

To complete the model, we need values for the shear strength of concrete. The most extensive set of data at this time still appears to be that of Chinn and Zimmerman, who give values of shear strengths of cylindrical concrete samples for mean normal stresses up to $7.5 \mathrm{~kb} .{ }^{5}$ More recent data obtained by the Waterways Experiment Station (WES) validated the older data but ranges only up to $3.5 \mathrm{~kb}{ }^{7}$ To complete the tensorial model, a guess is made for the yield strength of failed concrete of about a tenth of the virgin yield strength. According to WES, concrete "...is capable of a surprising amount of plastic deformation .... ${ }^{17}$ Consequently, we choose $10 \%$ plastic strain as the criterion for maximum failure. This completes the rudimentary model we use. More sophisticated models exist, but the paucity of data does not warrant the introduction of any more 'adjustable' parameters. One such variable might be to introduce rate dependencies for yield strengths.

\section{Future Work}

Our near-term plans are to insert the above concrete model into a code with an Eulerian capability such as CALE. This would permit us to calculate the effect of a munition that penetrates the concrete more deeply and is probably much more complicated hydrodynamically than the rebar cutter. The ease of performing calculations would be greatly improved, and parameter studies such as a study of the possible importance of rate effects would be greatly facilitated. A recalculation of the rebar approximations should make it possible to demonstrate major shear displacements at failure surfaces. Furthermore, the details of the surface crater formation and its resulting width could be reexamined, with the question of zoning definition of the crater wall removed from consideration. The result might provide additional insight into the spall of the front surface of the concrete in the vicinity of the bore hole. If our results continue to be encouraging, this will constitute a first version of a design tool that can calculate complete systems of munitions and targets self-consistently.

\section{Acknowledgements}

We thank Russell W. Rosinsky for providing analytic design data and Robert M. Kuklo for providing experimental details on the rebar-cutting charge for the PAM.

1. National Concrete Ready-Mix Association, Private Communication, Silver Spring, Maryland (October 1992).

2. R.W. Rosinsky, "An Annular Rebar Cutting Charge for the Penetration Augmented Munition," Munitions Technologry Development 1990, Sandia National Laboratories, Albuquerque, New Mexico, SAND90-1104 (1991).

3. J.O. Hallquist, User's Mamual for DYNA2D-m Explicit Two-dimensional Hydrodynamics Code zoith Interaction Rezoning and Graphical Display, Lawrence Livermore National Laboratory, Livermore, California, UCID-18756, Rev. 3 (1988).

4. V.G. Gregson, Jr., A Shock Wave Study of Fondu-Fyre WA-1 and a Concrete, General Motors Technical Center, DNA 2797 F (February 1972).

5. J. Chinn and R.M. Zimmerman, Behavior of Plain Concrete Under Various High Trinxinl Compression Loading Conditions, University of Colorado, WL TR 64-163 (August 1965).

6. N.C. Holmes, Private communication, Lawrence Livermore National Laboratory, Livermore, California (1992).

7. B.D. Neeley, M.I. Hammons, and D.M. Smith, The Development and Characterization of ComentionalStrength and High-Strength Portland Cement Concrete Mixture's for Projectile Penetration Studies, Waterways Experiment Station, Technical Report SL-91-15 (1991).

8. T. Tang, Behuvior of Concrete Under Dymamic Londing, Ph.D. Dissertation, University of Florida (1990).

9. Waterways Experiment Station, Private communication, Vicksburg, Mississippi (March 1992).

10. J.L. Levatin, A.V. Attia, and J.O. Hallquist, KDYNA User's Mantual, Lawrence Livermore National Laboratory, Livermore, California, UCRL-ID-106104 (1990).

11. D.E. Burton, L.A. Lettis, Jr., J.B. Bryan, and N. Frary, Physics and Numerics of the TENSOR Code, Lawrence Livermore National Laboratory, Livermore, California, UCID-19428(1982).

12. R.E. Tipton, CALE Ulser's Manual, Version 920721, Lawrence Livermore National Laboratory, Livermore, California (1992).

13. K.H. Sinz, "A Consistent Tensile Failure Treatment for Hydrocodes", unpublished (1987). 


\section{Benchmarking of the Criticality Evaluation Code COG}

\author{
William R. Loyd and \\ H. Peter Alesso \\ Fission Energy anut \\ Systems Sufity Program
}

\author{
John S. Pearson \\ Henlth and Safiety Dizision \\ Hazards Control Department
}

The purpose of our technology transfer project is to benchmark the Lawrence Livermore National Laboratory computer code COG for nuclear criticality evaluations. COG is potentially the most accurate computational tool available for these evaluations.

\section{Introduction}

Assurance of subcriticality is the most important element in any nuclear facility operation involving special nuclear materials. A good understanding of the detailed nuclear fission process is the only way to assure subcriticality. Today, this assurance is provided by using an analytical computational tool to evaluate and analyze all possible scenarios and geometries. The reliability of the evaluation results depends upon the accuracy of the computational tool in representing the realistic condition of the operation in question. Proof of the accuracy of the computational tool in turn depends upon the proper benchmarking of the code against actual nuclear fission process experimentsl (criticality experiments) similar to the operation being evalwated. The applicability of a code to a specific geometry and condition depends on whether a benchmark has been done for a similar type of experiment and how accurately the code predicts the result of the experiment.

The criticality evaluation code commonly used in both government and industry today is the KENO-Va code with the four cross-section sets arailable to it on the SCALE system, all developed at Oak Ridge National Laboratory (ORNL). Development of KENO began in the Mathematics Division of ORNL in 1958. In the 1970's and 1980's, the Nuclear Regulatory Commission funded the development of the SCALE system, a modular code system for performing standardized computer analyses for licensing evalu- ation. KENO, written more than 20) years ago, used methods as exaci as was possible at that time. Today, much better physical data are available, but these data do not fit the forms used by KENO.

Development of $\mathrm{COC}^{3}$ began in 1983 at Lawrence Livermore National Laboratory (LLNL) as a shielding code. The principal consideration in developing the code was that the resulting calculation was to be as accurate as the input data provided to the code. Cross-section data were presented by evaluators in the 1980's as point-wise data; i.e., as a series of cross-section points as a function of neutron energy, for example, with the understanding that interpolation between adjacent points produces results as good as the data. COG was written to use this form of the cross-section data directly. The angular scattering data are likewise presented and used as the evaluators present them. No approximation has been made that would compromise the accuracy of these data. The geometric description of a problem for input into a criticality code should be as exact as possible. $C O G$ permits specification of a surface defined by input analytic equations containing terms up to the fourth degree.

\section{Objectives}

COGi was developed on LLNL Cray Computers using the New Livermore Time Sharing System. COG is being moved from Crays to workstations that include the Hewlett lackard $(H I) 90(0) / 730$ and a SUN computer using the UNIX operating system for greater availability. 
COG and its cross-section set are being benchmarked against at least 250 criticality experiments to understand the bias of COG in a range of criticality situations.

The transfer of COG from LLNL to universities, industry, and other Department of Energy laboratories will be accomplished by placing it in the Nuclear Systems Safety Center (NSSC). Criticality and shielding services using COG can be offered from this system.

COG geometry input preparation can be tedious for complicated geometrical systems. The three-dimensional computer-aided-design (CAD) software Pro/ENGINEER and the LLNL code Pro/COG will be used to generate geometry input for COG.

\section{Progress}

COG has 160 subroutines that include 47 geometry subroutines and 86 cross-section subroutines. In May 1992, COG was compiled, assembled, and run on an HP 9000/730 computer. Further detailed checks of capabilities in COG, such as Russian roulette, path stretching, and importance weighting, were initiated on the HP 9000/730.

Preparation of 100 critical experiment models as input to COG were completed and run on LLNL Cray computers using LLNL Evaluated Neutron Data Library (ENDL) cross sections.

The Evaluated Nuclear Data File/B-V (ENDF/B-V) was converted from its parameterized format to a point-wise format suitable for use with COG. Techniques developed in this work will also permit conversion of other evaluated neutron libraries, including ENDF/B-VI, the Japanese Evaluated Neutron Data File-3 (JENDL-3), the Joint European File-1 (JEF-1), and BROND-2 (a Russian file). Benchmarking activities will provide criteria for unifying these evaluations into a single nuclear data library.

Output from the CAD software Pro/ENGINEER was combined with LLNL's Pro/COG to produce some COG geometry input for arrays of nuclear fuel rods.

\section{Future Work}

COG currently runs on an HP 9000/730 workstation with a UNIX operating system. Conversion of COG to run on a SUN Microsystems model S10MX is planned. Completed testing of the deep-penetration and code-optimization features is planned on both computers.

The running of models from at least 250 benchmark critical experiments is planned for the SUN and HP workstations.

Continued use of Pro/ENGINEER and development of the LLNL code Pro/COG to produce COG geometry input for arrays of fuel rods, the torus, and the sphere are planned.

Establishment of the NSSC is planned to provide a mechanism for exporting COG to other laboratories, universities, and industry.

\section{Acknowledgements}

The authors wish to recognize the individual contributions of C. Annese, R. Buck, D. Cullen, P. Giles, S. Hadjimarkos, D. Heinrichs, R. Howerton, D. Lappa, E. Lent, D. Resler, T. Wilcox, and R. White.

1. B.L. Koponen, T.P. Wilcox, Jr., and V.E. Hampel, Nuclear Criticality Experiments from 1943 to 1978, An Annotated Bibliography, Vols. 1-3, Lawrence Livermore National Laboratory, Livermore, California, UCRL-52769 (1979).

2. SCALE: A Modular Code System for Performing Standardized Computer Analysi's for Licensing Evaluation, NUREG/CR-0200, Revision 4 (ORNL/ NUREG/CSD-2/R4), Vols. I, Il, and III (1991); available from Radiation Shielding Information Center as CCC-545.

3. T.P. Wilcox, Jr. and E.M. Lent, COG-A Particle Transport Code Designed To Solve the Boltzmann Equation for Deep-Penetration (Shielding) Problems, Vol. i-User manual, Lawrence Livermore National Laboratory, Livermore, California, M-221-1 (1989). 


\section{Fast Agorithm for Large-Scale Consensus DNA Sequence Assembly}

\section{Shinyee Lu}

Engrinerving Resumch Dizision

Electronics Enginetring

\section{Ebert W. Branscomb \\ Bionnetical Scinnces Division}

the

\author{
Michael E. Colvin and \\ Richard S. Judson \\ Center for Computational Engineering \\ Sandiar National Laboratory \\ Lizernurer', Californin
}

A major current objective of the Human Cenome Center at Lawnence Livermone National Laboratory is completion of the physical map for chromosome 19. In the coming years, mone emphasis will be given to completely sequencing stretches of DNA and to analyzing these sequences. The goal of our effort is to develop algorithmic and computational tools needed to meet new challenges that will arise from this shift of emphasis.

This article describes our approach, called 'key-search,' to DNA sequence assembly. The computational complexity of the key-seanch algorithm is nearly directly proportional to the number of DNA bases to be assembled. We have completed the implementation of the algorithm. We are now testing our assembly program, using a data set provided by the National Institute of Health.

\section{Introduction}

The process of DNA sequencing is typically accomplished by using a so-called shotgun sequencing' approach. The method invele'es secuencing randomly overlapping small fragments $(20)$ to $5(x)$ base pairs) taken from a much larger piece (e.g., $4(0,()(0)$ base pairs), to a 5 -to lo-fold redundancy; i.e., the total number of base pairs sequenced is 5 to 10 times the size of the original piece. The original large sequence can be recovered in principle by pasting togrether fragments that shore common subsequences.

Seconence assembly is computationally difficult for two reasons. First, there are a large number of fragments ( $(10 x)$ or greater); a direct comparison of every pair todetermine which pairs containcommon subsequences is very slow. The exeond problem arises because' of errors in data collecting, imperfections in the fragmentation procesises, and the statistical nature of fragment selection. Existing methexts use sey juence alignment programs to determine overlap between fragments, and optimization methods to paste overlapping fragments together. These meth- oxts generally do not perform well for asisembling large serjuences.

Wehavedeveloped a new approach to the assembly problems, using a 'key-search' methext based on the computer science idea of hash tables. We first encexdecevery 15-base segment of every fragment into an integer called a key. These keys are sorted and stored in a table, together with pointers to the fringments in which they were found and the locations along these fragments. Starting from any key, one can determine the adjacent key (e.g., to the right) in the original sequence by examining all of the fragments that contain the current key (i.e., bases 1 to 15), generating a consensus for the next base (i.e., base 16). The next key is generated from bases 2 to 16 . The process is repeated key by key until an end condition is detected. Similarly, we can reconstruct the sequence to the left of the starting key. Figure 1 illustrates the basic concept of this approach. Extensions such as using consensus calculation at each base for automatic error correction, and methoxds for resolving the confusion that may be calused by motifs, pericodic patterns, and long repeats are added to increase the robustness of the assembly program. 


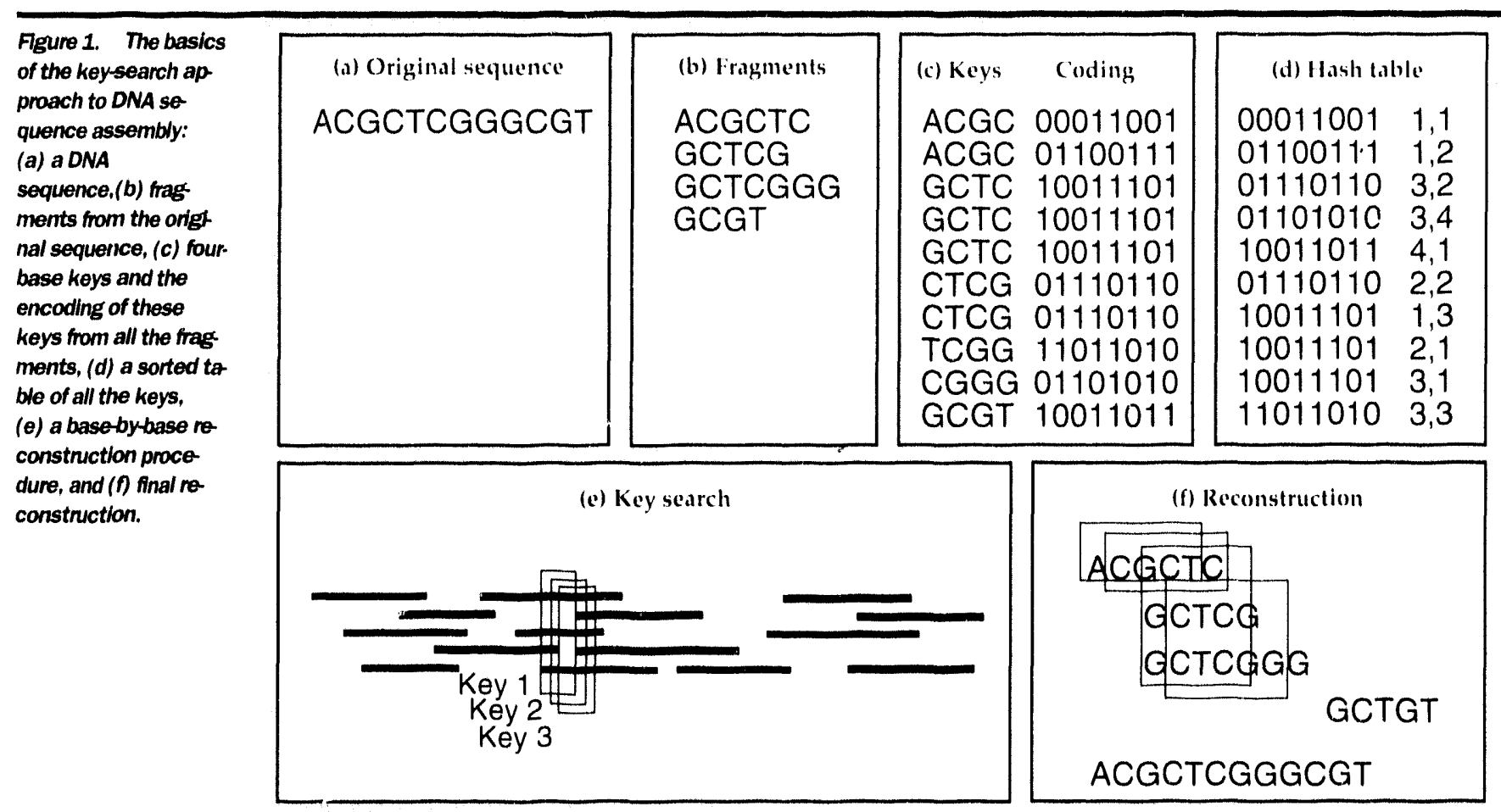

The major advantages of our approach are its computational efficiency and its potential forgeneriating more reliable reconstructions. Our methext can generate a complete consensus seyuence, the exact lexation at which each fragment resides along the consensus serfuence, and lixations where errors (xcur. This information provides necessory data for a statistical estimation of onficlene in the reassemblent seyuence. Biologists consider such estimation critical for their applications, and often fault current asixmbly methoxts for lacking the ability to provide confidencestimation.

\section{Progress}

We have completed the implementation of the key-search algorithm and testert it on a known DNA sequence of approximately $33,(x)(x)$ bas se pairs to validate the approach. A frigmentation program that simulates shotgun seyuencing and generates a symthetic tragment database was implemented. Wo typically assume l(t)-fold coserage, $2(x)-t()+f(x)$-bases-pair fragment length, and random cutting sites. We then compt the seyuence with errors at a realistic mate based on published data. Errors increase exponentially along the length of the fragment, from $1 \%$ for length below 2(x) base pairs to 7 ". at $5(x)$ base pairs. Our assembly program successfully reconstructs the complete sequence, except for a residual error rate of about 2" ". The recomstruction uxes less then H) minon a SUN Sparc Station II. We also tested the program with trangment data sets comrespending to less cover-

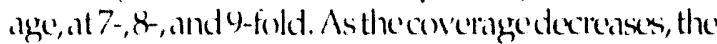
revonstruction can (m)ly generate islands, lexaluse some regiensof the original sejuence arenot cosered in the fragment database: Based on Monte Carlo simulation, 10-foldeoverage is the minimum reyuired tocoser the entireseyuence.

Our current task is to reconstruct a large secpuenoe from an actual friggment data set provided to us by the National Institute of Health (NII1). The NIH database has a relatiody low coserage of 5-to (o-fold, w)wernticipate finding gaps in theoriginal sepuence. Howerer, the rexonstruction coxte is able to generate $x$ 'veral islands in the $(x)(x)-$ to $10,(x)(x)-b a x^{2}-p a i r$ size range, for a total seyuence of approximately $34,(x)()$ basepairs. The reronstruction result will beevaluated by biologists at the Human Cienome Center at L alwrence Livermore Nationall aboratory (I.I.NI).

\section{Future Work}

Real fragment data sets are currently being generated at the L.LNL. Human (iennme Center. We will test the assembly program on these data. We will also compare our reconstruction results with results generated by other a ailable soltware packages such as the seceuence analysis software from Intelligenetics, lnce, and the sticten parkage from Cambridge University. 


\title{
Using Electrical Heating To Enhance the Extraction of Volatile Organic Compounds from Soil
}

\author{
H. Michael Buettner and \\ William D. Dally \\ Enginering Research Dizision \\ Electronics Enginering
}

We have developed a method of using electrical soil heating in combination with vacuum venting to enhance the removal of volatile organic compounds from contaminated soil. The results of two engineering-scale tests show that this technology has great potential for environmental remediation at both government and private facilities.

\section{Introduction}

The problem of contamination of ground water and woil by volatile organic compounds (VOC's) is widespreat in this country. Vacuum venting has long been usey as a remextiation methext in such cass. We proposed that electrical soil heating (joule heating) could be usert in combination with vacuum venting to enhance the removal of VOC's. We describe here the results of work to demonstrate electrial heating of the ground in engineering-sale tests for use as an adjunct to lacuum venting (or cyclic steam injection for the remosal of $V O X^{\prime}$ 's from soril.

\section{Progress}

We performed two engineering-scale tests. The first of these, in September, 1991 at an uncontaminated site, Sandia National Laboratories, Livermore, California, proved that sols can beeffectively heated using powerline-frepuency energy. The sec(nnd test, from May to July, 1992 at Lawrence Livermore National Laboratory's (LLNL) Site 30), which is contaminated with trichlorecthylene (TCE), proved that electrical heating can enhance VOC removal from soils.

Ourpurposes were (1) tolearn about the practical aspects of electrical heating such as selection and sizing of electrode materials and wires, and maintenance of low contact resistance between the electrodes and the ground; (2) to compare actual heating rates with those based on simple calcula- tions; (3) to provide data for scaling the experiment up for application at other contaminated sites; (4) to provide data for estimates relating to the economics of electrical heating; and (5) to demonstrate that electrical heating enhances extraction of $V O C^{\prime} s$ and to quantify the effect.

For our first engineering-scale field test, at an uncontaminated site, we used a pattern of six heating wells equally spaced on the circumference of a circle with a diameter of $6.1 \mathrm{~m}(20 \mathrm{ft})$. The electrodes were made of stainless steel tubing sections, and the contact resistance was maintained at a low value by saturating the sand pack around the electrode with water via a feed tube. The heating wells were powered with 3 -phase, 4()()-V, 60)-Hz power supplied by a 125-kVA generator.

Fixed themoxouples were usext to monitor the temperature as a function of time during the test. We ran the test around the dock for 10.76 days, then during the day only for four additional days. The currents to the electrodes, and thermocouple temperatures were monitored on a regular basis. At the end of the $24-h /$ day heating period, the temperature in the center of the pattern (the coldest point) at a depth of $4.88 \mathrm{~m}$ ( $16 \mathrm{ft}$ ) rose from a starting value of $19^{\circ} \mathrm{C} \mathrm{to}$ $38 \mathrm{C}$. During the daytimem ture rose to $44^{\circ} \mathrm{C}$. At this point, the power was tumed off, and the temperature continued to rise to $54^{\circ} \mathrm{C}$ in a 10-day period, after which we stopped temperature monitoring. Other thermocouples nearer to the $p^{2}$ riphery rond as high as $73^{\circ} \mathrm{C}$. These experimental results agree doscly with very simple calculations 


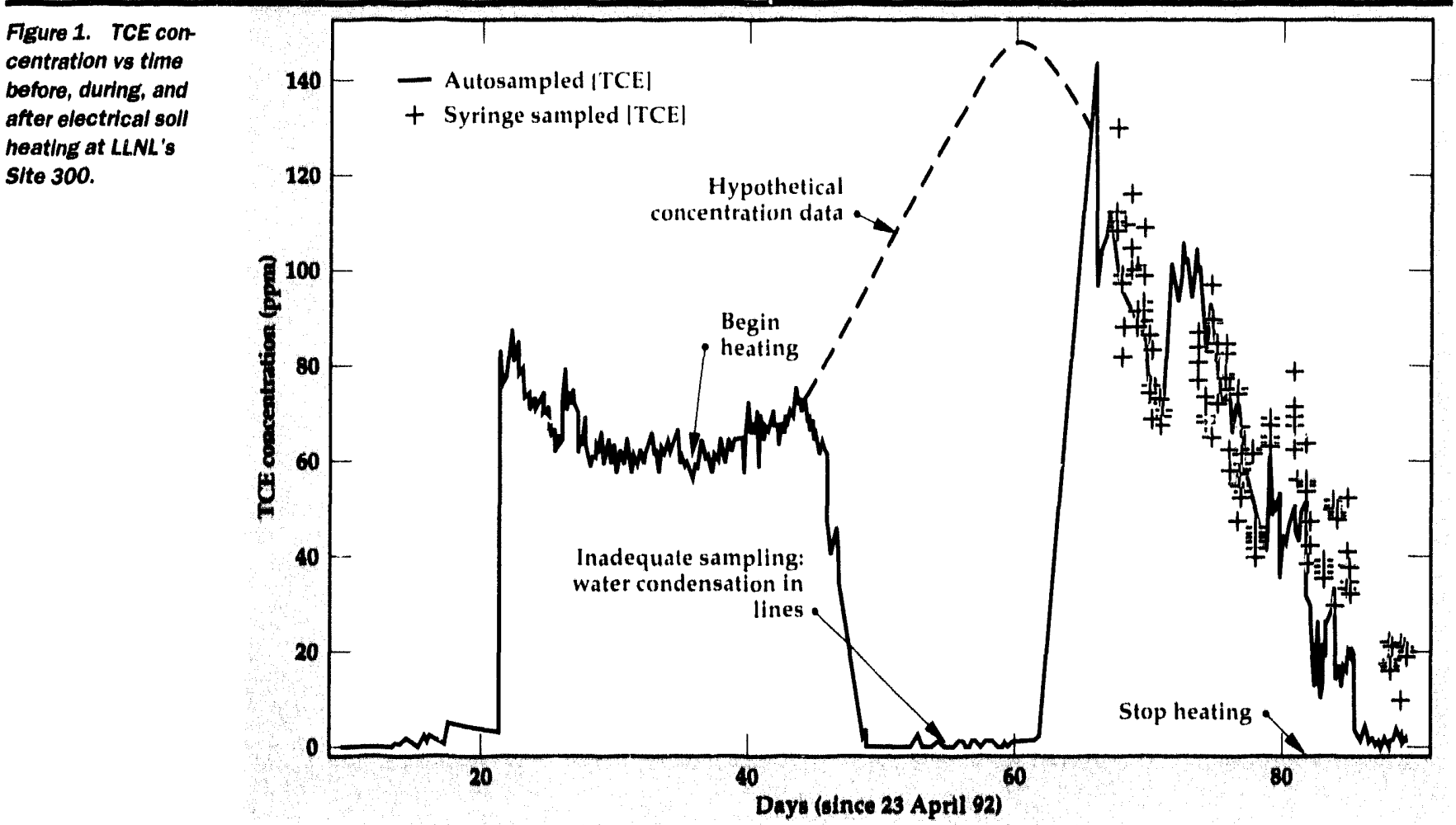

based on a twordimensional model, assuming hor mogenerus el:.:trical and thermal properties. Over the duration of tive heating phase of the experiment, the total energy dissipated in the ground was about $15,(0) 0) \mathrm{kWh}$.

For our second test, at a site contaminated with TCE, the heating wells were also located on a 6.1-m circle. A vapor extraction well was located in the center of the pattern. The heating wells were powered with 3-phase, 48()-V, 6)-Hz power supplied by a 100-kVA generator. Again, the contact resistance of the electrodes was maintained at a low value by saturating the sand pack around the electrode with water via a feed tube.

We ran the test during the day only for 4 () days. The currents to the electrodes and thermocouple temperatures were monitored regularly. During the heating phase of the experiment, the temperature of the vapors extracted from the central well rose from $16^{\circ} \mathrm{C}$ to $36^{\circ} \mathrm{C}$, and continued rising thereafter to $39^{\circ} \mathrm{C}$, when we stopped collecting data. The TCE concentration in the collected vapor decreased steadily as vacuum was applied to the central well during the period before heating, to a low of about $60 \mathrm{ppm}$. Once electrical heating began, the concentration increased. The concentration rose to over $140 \mathrm{ppm}$ during the heating period, and then decayed to values of less than $20 \mathrm{ppm}$. Resulis areshown in Fig. 1. The amount of electrical energy depensited in the ground was about $9600 \mathrm{kWh}$.
The lessons learned as a result of this work have been applied to a much larger and highly visible project at LLNL, the Dynamic Underground Stripping Project. ${ }^{1,2}$ This project seeks to clean up approximately 17,000) gallons of gasoline from the soil and ground water at an old gasoline station site. In this demonstration project, steam injection and vacuum extraction are used to clean gasoline from the sands and gravels, while electrial heating drives the gasoline from the clay layers.

\section{Future Work}

The technology we have developed has great potential for the Department of Energy (DOE) and for the private sector. LLNL is at the forefront of this work. We are actively seeking partners inside and outside DOE for further development and/or licensing of the technology. For example, the technology is being considered for remediation work at the DOE's Rocky Flats, and for facilities of British Petroleum of America.

1. R. Aines and R. Newmark, "Rapid Removal of Underground Hydrocarbon Spills," Emergy and Ticlunology Rericioi, Lawrence Livermore National Laboratory, Livermore, California (July 1992).

2. "Ground water cleanup researchers make headway," Nenesline', Lawrence lifiermore National Laboratory, Livermore, California (October 2, 1992). 


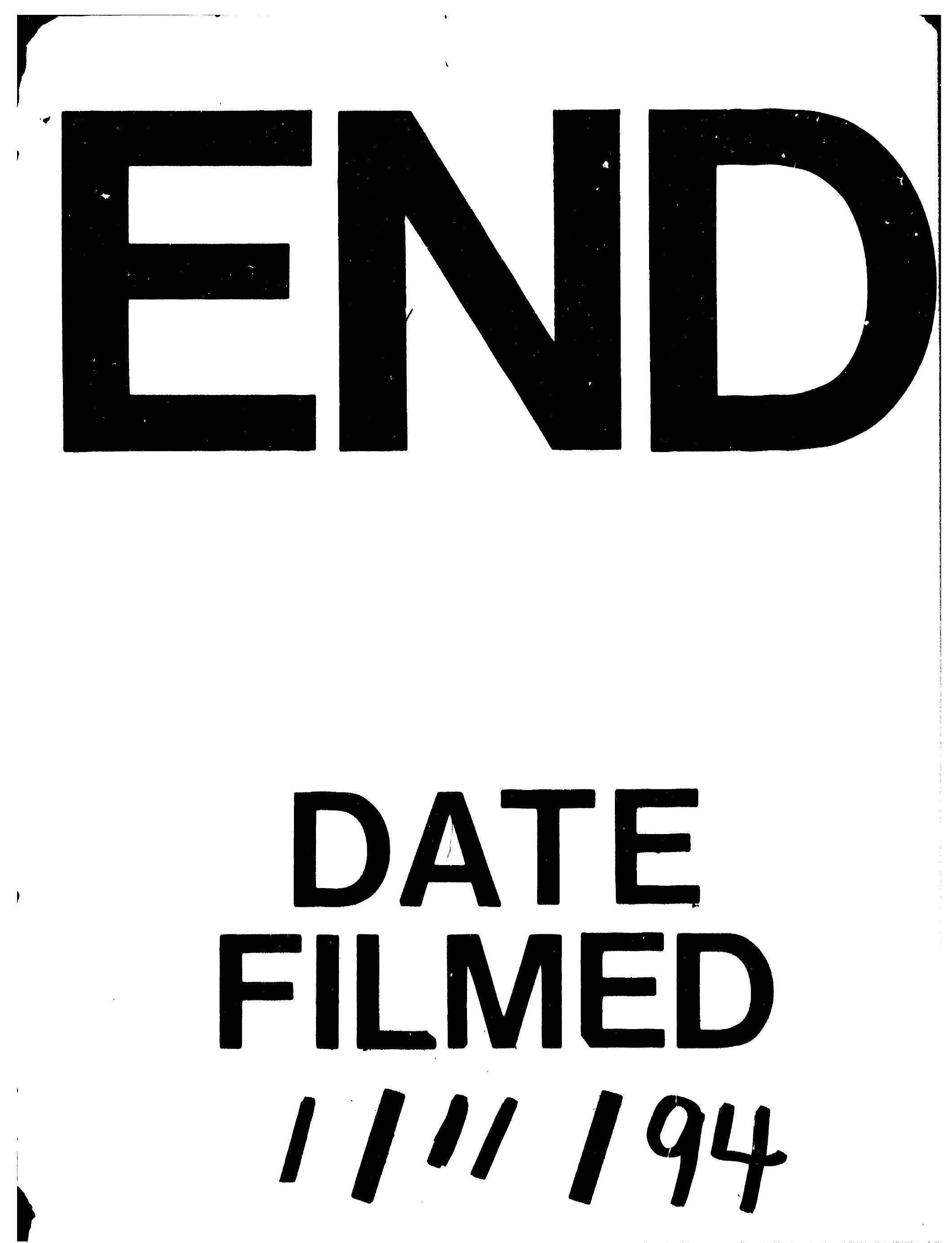


$\vdots$

: 